\title{
High-cycle fatigue constitutive model and a load-advance strategy for the analysis of unidirectional fiber reinforced composites subjected to longitudinal loads
}

\author{
Lucia G. Barbu $^{a, b, *}$, Sergio Oller ${ }^{a, d}$, Xavier Martinez $^{a, c}$ and Alex H. Barbat ${ }^{a, b}$ \\ a. International Center for Numerical Methods in Engineering (CIMNE). Campus Nord, Gran \\ Capità s/n, 08034 Barcelona, Spain \\ b. Department of Strenght of Materials and Structural Engineering - UPC. Edifici C1, Campus \\ Nord, Jordi Girona 1-3, 08034 Barcelona, Spain \\ c. Department of Nautical Science and Engineering - UPC. Pla de Palau 18, 08003 Barcelona, \\ Spain \\ d. CONICET-UNSa (Consejo Nacional de Investigaciones Científicas y Técnicas), Salta, \\ Argentina
}

*Corresponding author. Tel +34 934016473, e-mail: 1gratiela@cimne.upc.edu

\begin{abstract}
A fatigue constitutive model valid for the composite constituent will be presented in this paper. The composite behaviour will be obtained by means of the serial/parallel mixing theory that is also used as a constitutive equation manager. The constitutive formulation is coupled with a load advancing strategy in order to reduce the computational cost of the numerical simulations. Validation of the constitutive formulation is done on pultruded glass fiber reinforced polymer profiles. Special emphasis is made on the comparison between the experimental and the numerical failure mode.
\end{abstract}

Key words: High cycle fatigue, Mixing theory, Fiber reinforced composite, Continuum damage mechanics, Load-advance strategy, Post elastic behaviour.

\section{INTRODUCTION}

The need to apply continuum damage mechanics-based models to composite materials has been widely recognized. Efforts to conduct fatigue analysis of large structures have been hindered by excess computational time and the inability to separate differences in constitutive behaviour exhibited by each constituent of the composite. Historically, only micromechanical models have been able to treat the constituent separately. Thus, handling component material failure at a large-scale structural level was nearly impossible.

In general, the lack of understanding regarding composite structural fatigue is a significant setback for many industries. Fatigue failures represent the greatest uncertainty with regard to the long term service lifetime of the major structural components of a wind turbine [1].

The failure mode that will be addressed in this paper is the life prediction of composites when they are subjected to cyclic loads. The effect of fatigue in composites is a controverted issue due to the fact that fatigue is a concept traditionally associated to the crystalline structure.

From a phenomenological point of view, if we understand fatigue as damage accumulation due to an increase in the number of loading cycles, the concept can be extended to composite materials.

There are three commonly used approaches when assessing life duration for a composite material [2]:

- $\quad$ Strength reduction models

- $\quad$ Stiffness reduction models

- $\quad$ Effective damage models

Assuming that the strains and stresses at constituent level can be determined either by a micromodel or by simplifying theories (among which mixing theory can be considered), strength reduction models require a large number of experimental failure tests. Even so, they are traditionally the most commonly used methods [2]. 
Stiffness reduction models have the advantage that, although a large number of experimental data is still needed, the testing can be done without fracturing the samples.

Effective damage models are developed starting from the early work of Kachanov [3] under the CDM framework for ductile damage.

In a composite material, fatigue damage can take the form of any or all of the following: delamination, matrix cracking, matrix crazing, fiber/matrix debonding and void growth [2].

There are numerous studies, most of them experimental, that address this problem showing that the life prediction varies depending on the composite constituents (there is a difference between using glass or carbon fibers [4]); as well as it also varies depending on the composite configuration, such as fiber orientation [4] or in case of ply-drops [5]. This variability proves that the life prediction of composites subjected to cyclic loads cannot be addressed just with an $\mathrm{S} / \mathrm{N}$ curve but it requires a detailed simulation capable to take into account all dependencies.

To meet the needs of composite structural evaluation, an effective solution to accurately model composite fatigue should [6]:

- Consider fatigue damage to a particular constituent material within the composite, not damage to the homogenized composite.

- $\quad$ Require a minimal input data set for characterization of fatigue behaviour.

- $\quad$ Apply to multiple types of loading and load histories.

- Apply to any composite laminate layup.

Early studies in predicting composite fatigue such as Hashin et al. [7] relied on macroscopic composite strengths. This approach requires a minimal data set, but satisfies none of the other requirements.

Microstructural modelling of a composite can yield high-fidelity constituent stresses and strains but is too computationally intensive for large-scale structural analyses. The different micromechanical damage modes that appear in composites after fatigue loading are considered in this approach. A first attempt considering dominant crack propagation has been presented by Halpin [8]. Reifsnider [9]-[13] developed a model based on critical and subcritical elements in the laminate, investigated by researchers like Song and Otani [14], trying to correlate critical strengths of the composite with various microdamage mechanisms, while the Charewicz and Daniel [15] approach in predicting residual strength uses an unidentified damage function. An interesting experimental study suggesting a possible correlation of damage mechanisms with load sequence effects and their impact on lifetime prediction was developed by Gamstedt and Sjögren [16].

The microstructural models claim to offer a long-term promise and to be applicable to a wide variety of materials, lay-ups and loadings with a minimal amount of experimentally obtained input. At present however, they are either in their infancy or have been applied to simple fatigue loading or else include micromechanical parameters, which are difficult to obtain in structural engineering reality [17].

More complex macroscopic approaches, such as calculating residual strength or residual stiffness, have also been used, but they require much more experimental data and still apply only to a particular laminate. The results suggest that some of the models are able to describe in several cases the phenomenon of strength degradation, while others fail to provide consistently a good prediction of this behaviour, i.e. for the various tested life fractions of the coupons under different loading conditions and for all the laminate cases studied. For instance, the linear strength degradation model of Broutman and Sahu [18], modified to account for material non-linear degradation behaviour by introducing an additional parameter as shown in [17] and the deterministic model by Harris and co-workers [19], also enhanced with statistical features models, in most cases predict satisfactorily the residual strength of the materials considered. However, they require a considerable experimental effort for implementation and do not consistently produce safe predictions. From the point of view of the designer, the approach of the linear model of Broutman and Sahu [18] appears as a strong candidate for either glass/epoxy or carbon/epoxy laminates, at least when tensile fatigue is considered.

It is important to note that it seems that no residual strength model can be safely used universally. This is mainly due to the large scatter of the residual strength data and the simultaneous initiation and propagation of several damage mechanisms in the composite under fatigue loading.

Moreover, nearly all of these techniques require a large amount of experimental data to characterize the material. Most predictive theories pertain to a specific load history at a specific temperature and are not easily generalized to capture multiaxial load states or variable amplitude loading. In addition, any general 
solution must be able to be implemented into finite element codes, with computational efficiency.

The chosen approach in the present work is a strength reduction model at constituent constitutive level based on the formulation adopted for metals under cyclic loading condition [20][21]. The stresses and strains of the composite constituents are calculated using a modified serial/parallel mixing theory (SP RoM) [22], which allows different constitutive behaviour for each of the composite components and can accurately model delamination effects, which are expected to be a consequence of fatigue damage. This theory is based on the definition of some compatibility equations between the strain-stress states of the composite constituent materials. In the case of a composite made of fibre and matrix, what the Serial/Parallel mixing theory does is to impose an iso-strain condition on the parallel direction, chosen usually as the fibre direction, and an iso-stress condition on the serial direction, usually the remaining directions of the stress and strain tensors. With this scope, if the matrix structural capacity is lost, the Serial/Parallel mixing theory will reduce the structural capacity of fibre material in the serial directions due to the iso-stress condition. Thus, it will be impossible for the composite layer to develop shear or transversal stresses, less to transmit them to the surroundings elements. It has been already proved by Martinez et al. [23] that the structural failure just described is equivalent to a delamination failure. The approach presented here is valid for unidirectional composites that are in fact at the basis of composite laminates. Therefore, this procedure is suitable for assessing damage in laminates. A parallel behaviour is considered in between the laminae in that case, meaning that all of them share the same strain tensor. This strain tensor is then the input for the SP RoM analysis conducted inside the laminae. The formulation then is capable of taking into account different damage behaviours for each of the components of the laminae and in each component a different stress state is found as o consequence of the decomposition performed by the SP RoM.

The fatigue damage model used for each component is described in detail herein. It is based on the S$\mathrm{N}$ curves at component level. After solving the $\mathrm{FE}$ system of equations and deriving the displacements at each node of the structure, the strains at each integration point are computed for each composite material. With the help of the SP RoM this strain state is decomposed into strain tensors for each component and afterwards with each component constitutive model the stresses are integrated. Therefore, at each integration point in the FE model, inside its composite material different stress reversion factors will be computed for both components at each time step. An associated S-N curve will be automatically derived for the composite component at that moment in time and for that level of stress.

At this point, it is important to specify that the formulation developed in this work is not valid for woven composites as it is not able to capture the complex interaction occurring at microstructural level between its components. No thermal effects were taken into account in the formulation.

The basis of the fatigue constitutive model was initially developed by Oller et al. [24]. The model establishes a relationship between the residual material strength and the damage threshold evolution, controlled by the material internal variables and by a new state variable of fatigue that incorporates the influence of the cyclic load.

This constitutive model has been posteriorly developed for high cycle fatigue (HCF) in steel and included a load - advance strategy that allowed advancing by large loading steps. This work is focused on assessing its life prediction capability for HCF in composites while taking advantage of the load-advancing strategy. An overview of the constitutive formulation for the HCF case is provided in order to clarify the material behaviour exhibited in the numerical examples. Several model assumptions are to be made. Defect concentration on the microscale occurs during the whole period of cyclic loading. This is reflected in the model in a continuous reduction of material strength, occurring even in the elastic stage. Stiffness degradation occurs only in the post critical stage, once the S-N curve has been passed and, therefore, only in the final stage before failure. The damage parameter has a phenomenological significance indicating the irreversibility of the fatigue process.

Regarding the high cycle fatigue (HCF) phenomenon, it is known that the type of fracture involved at macroscale level occurs with little or no plastic deformation [20]. Therefore, HCF does not introduce macroscopic plastic strain, but it introduces porosity [25]. These are the reasons that have led to describe this failure mode by means of damage models. These can be categorized into five groups: damage curve approach, crack growth-based approach, life curve modification approach, energy based damage theories and continuum damage mechanics (CDM) approaches [26]. However, in spite of the great number of 
models proposed in the HCF field, there is not yet a universally accepted one.

In particular, the CDM approach is based on the original concepts of Kachanov [3], [27] for treating creep damage problems. The posterior work of Chaboche [28], [29], Chaboche and Lemaitre [30], [31], Wang [32], Wang and Lou [33], Li et al. [34] and Oller et al. [24] established the CDM framework as a valid alternative to the fracture mechanics formulations in order to assess in a unified way both crack initiation and propagation. Furthermore, they enhanced the study of fatigue problems by recognizing that the theoretical structure of continuum mechanics, such as damage, is suitable for the study of nonlinear fatigue problems and that the mechanical effect known as fatigue produces a loss of material strength as a function of the number of cycles, load amplitude, reversion index, etc.

As stated by Li et al.[35], the first known treatment of damage characterization by internal variables in a CDM formulation for composites was that of Talreja [36] who recognized that in fibre-reinforced composite materials, individual micro-cracks have specific orientations. A more recent CDM formulation, [38] continued this approach to damage characterization.

Other approaches have used a consequence of damage, e.g. the change in the Young's modulus as a damage variable. A comparative study of several damage descriptions is given in Voyiadjis and Kattan [37]. The damage mechanics field remains active to this day, as evidenced by recent publications such as [39]-[42].

An alternative way for dealing with fatigue crack growth problems is using the cohesive zone model. This model is commonly adopted for the simulation of quasi static fracture problems, especially in the case of interface cracks such as in bonded joints and delamination in composites [46]. The possibility to simulate the growth of a crack without any remeshing requirements and the relatively easy possibility to manipulate the constitutive law of the cohesive elements makes the cohesive zone model attractive also for the fatigue crack growth simulation such as Turon et al.[43], Khoramishad et al. [44], Harper and Hallett [45] and Giuliese et al. [46]. However, cohesive zone models do not take into account different specific behaviors for each component of the composite and do not take into account the load history which is an important factor in considering damage evolution. A comprehensive review on the topic and on different linear and nonlinear damage models for composite materials can be found in Rubiella et al.[47].

Regarding fatigue life prediction, many different approaches have been proposed such as the early methods of stress-life approach and strain-life approach [48]. One of the most used models is based on the Palmgren-Miner linear damage law [49], [50]. However, such models do not recognize the effects of prior history of loading, or the load sequence on the subsequent life, either. Strain-life models, on the other hand, account for the local plasticity effects at stress concentrations regions [51]. Information is abundant in literature, as there are many different crack initiation models [52], with a large number of empirical models proposed for the long crack growth prediction [53] or, recently, crack density under static and fatigue loading in Llobet et al. [54].

The new formulation this paper presents is validated on pultruded glass fiber reinforced polymer profiles by comparing experimental values with the values obtained from a numerical simulation. The following section describes the serial/parallel mixing theory used, the SP RoM, and how it is implemented in a finite element code. The next section then presents the damage formulation, capable of taking into account the residual strength of a delaminated composite due to the friction between the delaminated surfaces. The following section describes the test simulated. The results obtained from the simulation are studied and compared to the experimental ones. Finally, last section presents the conclusions drawn from the simulation performed.

\section{FATIGUE DAMAGE MODEL}

A brief description of the constitutive model used in this paper is offered in this section. The fundamentals of a fatigue continuum damage model are presented with a clear emphasis on the model's dependence on S-N curves. An exhaustive description of the formulation used can be found in Oller et al. [24], where the complete thermo-mechanical constitutive model for the prediction of fatigue effects in structures is formulated. The model is capable of taking into account the combined effect of mean stress and multi-axial stress states. The treatment of the highly complex processes generated by fatigue is made from a phenomenological point of view. 


\subsection{Mechanical damage formulation}

The free Helmholtz energy is formulated in the reference configuration for elastic Green strains, $E_{i j}=E_{i j}^{e}$, as [55], [56]

$$
\Psi=\Psi\left(E_{i j}, d\right)=(1-d) \frac{1}{2 m^{0}}\left(E_{i j} C_{i j k l}^{0} E_{k l}\right)
$$

where $m^{0}$ is the material density, $E_{i j}=E_{i j}^{e}$ is the total strain tensor, $0 \leq d \leq 1$ is the internal damage variable taking values between its initial value 0 and its maximum value 1 and $C_{i j k l}^{0}$ is the original constitutive tensor.

Considering the second thermodynamic law (Clausius-Duhem inequality - [57], [58], [59]), the mechanical dissipation can be obtained as [55]

$$
\Xi=-\frac{\partial \Psi}{\partial d} \dot{d} \geq 0
$$

The accomplishment of this dissipation condition (Equation (2) demands that the expression of the stress should be defined as (Coleman method; see [59])

$$
S_{i j}=m^{0} \frac{\partial \Psi}{\partial E_{i j}}=(1-d) C_{i j k l}^{0} E_{k l}
$$

Also, from the last expressions, the secant constitutive tensor $C_{i j k l}^{s}$ can be obtained as:

$$
C_{i j k l}^{s}(d)=\frac{\partial S_{i j}}{\partial E_{i j}}=m^{0} \frac{\partial^{2} \Psi}{\partial E_{i j} \partial E_{k l}}=(1-d) C_{i j k l}^{0}
$$

where $S_{i j}$ is the stress tensor for a single material point.

\subsection{Threshold damage function oriented to fatigue analysis. Phenomenological approach}

The effects caused by applying an increasing number of loading cycles are taken into account by means of a proposed $f_{\text {red }}\left(N, S_{\max }, R\right)$ function. This function is introduced in the above formulation in the expression of the damage threshold surface, $F^{D}\left(S_{i j}, d\right)$, proposed by [59], [60] and [61]. The number of cycles $N$ can then be incorporated as a new variable. This enables the classical constitutive damage formulation to account for fatigue phenomena by translating the accumulation of number of cycles into a readjustment and/or movement of the damage threshold function.

The non-linear behaviour caused by fatigue is introduced in this procedure implicitly, by incorporating a fatigue state variable $f_{\text {red }}\left(N, S_{\max }, R\right)$, that is irreversible and depends on the number of cycles, the maximum value of the equivalent stress in the material $S_{\max }$, and on the factor of reversion of the equivalent

stress, $R=\frac{S_{\min }}{S_{\max }}$. This new variable affects the residual strength of the material by modifying the damage threshold, $F^{D}\left(S_{i j}, d, N\right)$, either on the equivalent stress function $f^{D}\left(S_{i j}\right)$ ( equation (5a), or on the damage strength threshold $\bar{K}^{D}\left(S_{i j}, d\right)$ (equation 5b) [24].

$$
F^{D^{\prime}}\left(S_{i j}, d, N\right)=\underbrace{\frac{f^{D}\left(S_{i j}\right)}{f_{\text {red }}\left(N, S_{\max }, R\right)}}_{f^{D^{\prime}}\left(S_{i j}, N, R\right)}-\bar{K}^{D}\left(S_{i j}, d\right) \leq 0
$$




$$
F^{D^{\prime \prime}}\left(S_{i j}, d, N\right)=f^{D}\left(S_{i j}\right)-\underbrace{\overline{K^{D}}\left(S_{i j}, d\right) \cdot f_{r e d}\left(N, S_{\max }, R\right)}_{K^{D^{\prime}}\left(S_{i j}, d, N\right)} \leq 0
$$

In the above, $f^{D^{\prime}}=f^{D} / f_{\text {red }}\left(N, S_{\max }, R\right)$, is the reduced equivalent stress function in the undamaged space, $K^{D^{\prime}}\left(S_{i j}, d, N\right)$ is the fatigue damage strength threshold, and $d=\int_{0}^{t} \dot{d} d t$ the damage internal variable. In the following, the formulation in equation ( $5 \mathrm{a}$ has been used for the damage threshold criterion.

Usually, instead of working with equations (5), the damage criterion is converted to an equivalent one by using a scalar function $\mathrm{G}$ which is positive and with its derivative positive, monotonously increasing and invertible:

$$
F^{D^{\prime}}\left(S_{i j}, d, N\right)=G\left[f^{D^{\prime}}\left(S_{i j}, N, R\right)\right]-G\left[\bar{K}^{D}\left(S_{i j}, d\right)\right\rfloor \leq 0
$$

The evolution of the damage variable is defined as

$$
\dot{d}=\dot{\mu} \frac{\partial F^{D}}{\partial f^{D}}
$$

being $\mu$ the consistency damage factor, which is equivalent to the consistency plastic factor defined in [55]. Consequently, for the isotropic damage case,

$$
\dot{d}=\frac{\dot{\mu}}{f_{\text {red }}}
$$

\subsection{Particularization of the damage threshold function for exponential softening}

The type of softening to be defined in the general damage criterion depends on the problem to be solved. The scalar function defining the evolution of the damage threshold must be monotonous and with a value ranging from 0 to 1 . In various publications about the scalar damage problem, the stress behaviour with softening is represented in a variety of forms. Particularly, in Oliver et al. [61] the following function is proposed:

$$
G\left[\bar{K}^{D}(d)\right]=1-\frac{\bar{K}^{D \max }}{\bar{K}^{D}(d)} e^{A\left(1-\frac{\bar{K}^{D}(d)}{\bar{K}^{D \max }}\right)} \text { with } 0 \leq \bar{K}^{D \max } \leq \bar{K}^{D}(d)
$$

This function can also be expressed as

$$
G\left[f^{D^{\prime}}\left(\mathbf{S}_{0}, N\right)\right]=1-\frac{f_{0}^{D^{\prime}}\left(\mathbf{S}_{0}, N\right)}{f^{D^{\prime}}\left(\mathbf{S}_{0}, N\right)} e^{A\left(1-\frac{f^{D^{\prime}}\left(\mathbf{S}_{0}, N\right)}{f_{0}^{D^{\prime}}\left(\mathbf{S}_{0}, N\right)}\right)} \text { with } \quad f_{0}^{D^{\prime}}\left(\mathbf{S}_{0}, N\right)=\bar{K}^{D \max }
$$

where $A$ is a parameter that depends on the fracture energy of the material and $f^{D^{\prime}}\left(\mathbf{S}_{0}, N\right)=\frac{f^{D}\left(\mathbf{S}_{0}\right)}{f_{\text {red }}\left(S_{\max }, N, R\right)}$. The value of $f_{0}{ }^{D^{\prime}}\left(\mathbf{S}_{0}, N\right)=\bar{K}^{D \max }$ is obtained from the fulfilment of the damage criterion for the first threshold of degradation. This complies with $G\left[f_{0}{ }^{\prime}\left(\mathbf{S}_{0}, N\right)\right]-G\left[\bar{K}^{D \max }\right]=0$ and $G\left[f_{0}^{D^{\prime}}\left(\mathbf{S}_{0}, N\right)\right]=G\left[\bar{K}^{D \max }\right] \equiv 0$.

The A parameter is calculated from the dissipation expression shown in equation $\Xi=\Psi_{0} \dot{d} \geq 0$, particularized for a uniaxial process subjected to a growing monotonic load. The parameter deduction can 
be obtained from [62] and has the following expression for exponential softening:

$$
A=\frac{1}{\frac{C_{0} g_{f}}{\left(\tau^{0}\right)^{2}}-\frac{1}{2}}
$$

\subsection{Function of residual strength reduction for fatigue - Wöhler curve definition}

Wöhler or "Stress-Num. of cycles" $(S-N)$ curves (Figure 1) are experimentally obtained by subjecting identical smooth specimens to cyclic harmonic stresses and establishing their life span measured in number of cycles. The curves depend on the level of the maximum applied stress and the ratio between the lowest and the highest stresses $\left(R=S_{\min } / S_{\max }\right)$. In Figure $1 \mathrm{~b} S_{\text {lim }}$ is the endurance limit for a reversion factor of -1 and $S_{f}^{0}$ is the material elastic limit. In Figure 1a the instantaneous stress level is depicted, while in Figure $1 \mathrm{~b}$ the cyclic stress is represented only by the maximum value it reaches in every cycle. Usually, $S-N$ curves are obtained for fully reversed stress $\left(R=S_{\min } / S_{\max }=-1\right)$ by rotating bending fatigue tests.
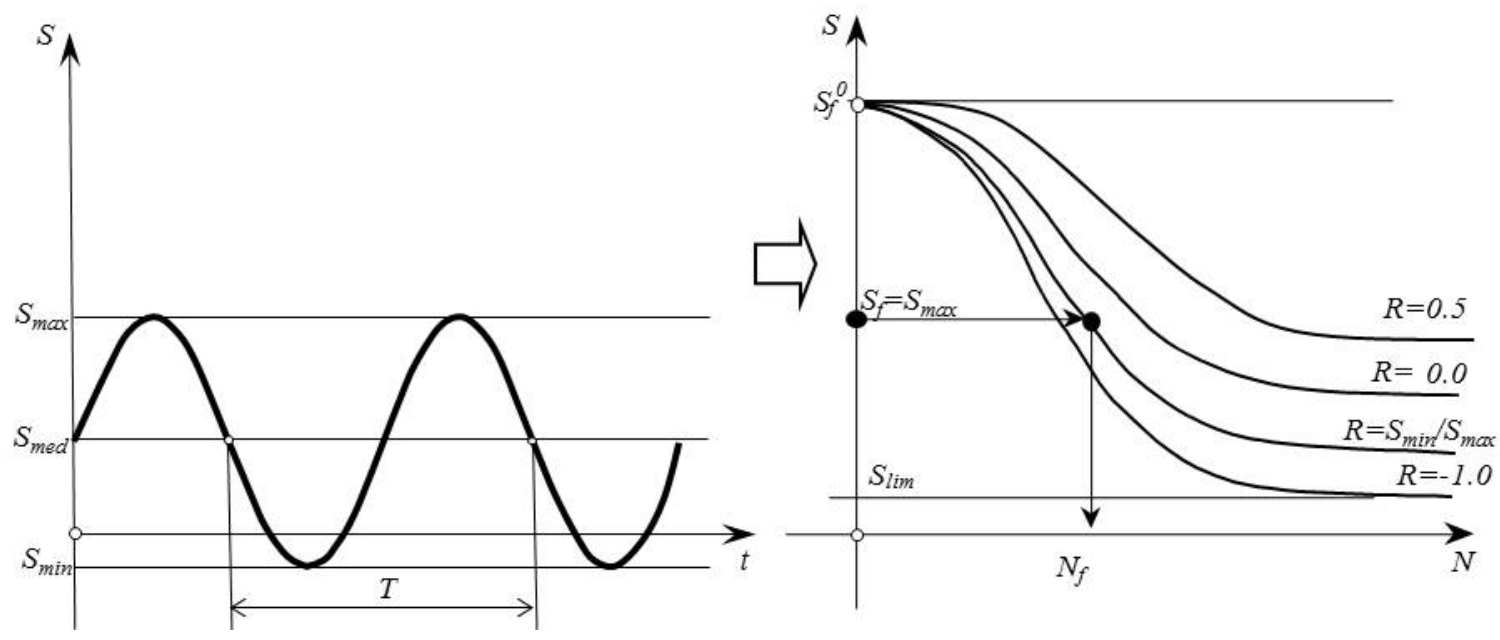

Figure 1 a: Stress evolution at a single point; b: S-N (Wöhler's) Curves

S-N curves are, therefore, fatigue life estimators for a material point with a fixed maximum stress and a given ratio $R$. If, after a number of cycles lower than the cycles to failure, the cyclic load stops, a change in the material's elastic threshold is expected due to accumulation of fatigue cycles. Furthermore, if the number of cycles exceeds $N f$, being $N f$ the fatigue life as resulting from Figure 2, the material will fail with the consequent reduction of strength and stiffness. The change in strength is quantified by the strength reduction function $f_{\text {red }}\left(N, S_{\max }, R\right)$, while the change in stiffness is taken into account by means of the damage parameter. In Figure $2 S_{e}$ is the endurance limit for any given reversion factor and $S_{t h}$ is the elastic threshold limit.

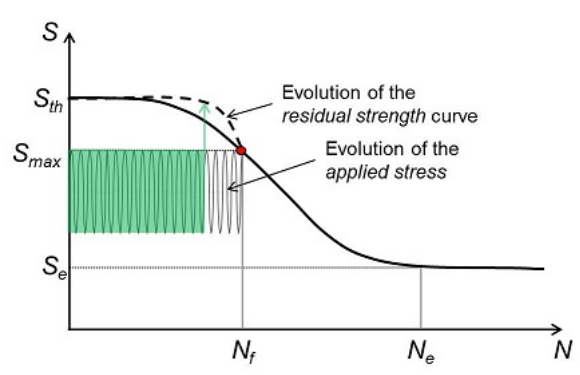

Figure 2: Schematic representation of the evolution of the residual strength with the applied load and number of cycles. 
In the case of a cyclic load with constant $S_{\max }$ and $R$ throughout the entire life of a material, the S-N curve is sufficient for determining fatigue life. However, when dealing with different load interactions the main focus resides on the residual strength curve. The curve quantifies the loss of strength in the material as the number of cycles accumulates and as load characteristics change.

All fatigue numerical simulations are based on the Wöhler curves obtained experimentally. These curves are described in an analytical form with the help of material parameters. Their expression, as well as the analytical definition of the strength reduction function, is connected to the experimental curve and, therefore, subjected to change if the material changes. Different analytical definitions can be found in [63], [64] and [65], as well as in [24].

The analytical formulation presented in [24] is shown herein. Based on the actual value of the $R$ ratio and a basic value of the endurance stress $S_{e}$ (for $R=-1$ ) the proposed model postulates a threshold stress $S_{t h}$. The meaning of $S_{t h}$ is that of an endurance stress limit for a given value of $R=S_{\min } / S_{\max }$.

$$
\begin{aligned}
& \text { if }|R| \leq 1 \\
& S_{\text {th }}(R)=S_{e}+\left(S_{u}-S_{e}\right) *(0.5+0.5 * R)^{\text {STHR } 1} \\
& \text { else } \\
& S_{\text {th }}(R)=S_{e}+\left(S_{u}-S_{e}\right) *(0.5+0.5 / R)^{S T H R 2} \\
& \text { end }
\end{aligned}
$$

If the actual value of $R$ is $R=-1$ then, $S_{t h}=S_{e}$. The effect of the number of load cycles $N_{c}$ on the ultimate stress $S_{u}$ for a given value of $R$ is taken into account by an exponential function:

$$
S\left(R, N_{c}\right)=S_{t h}(R)+\left(S_{u}-S_{t h}(R)\right) * e^{-A L F A T(R) * \log _{10} N_{c}{ }^{B E T A F}}
$$

The value of $A L F A T(R)$ is given by the function

$$
\begin{aligned}
& \text { if }|R| \leq 1 \\
& \operatorname{ALFAT}(R)=A L F A F+(0.5+0.5 * R) * A U X R 1 \\
& \text { else } \\
& \operatorname{ALFAT}(R)=A L F A F-(0.5+0.5 / R) * A U X R 2 \\
& \text { end }
\end{aligned}
$$

where ALFAF, BETAF, STHR1, STHR2, AUXR1 and AUXR2 are material parameters that need to be adjusted according to experimental tests. Figure 3 shows an example of application of these functions. Parameters were chosen as follows: $\mathrm{Se}=0.5 * \mathrm{Su}, A L F A F=0.0068, B E T A F=3.35, \mathrm{STHR} 1=0.7, \mathrm{STHR} 2$ $=0.5, A U X R 1=0.0133$ and $A U X R 2=0.0068$.

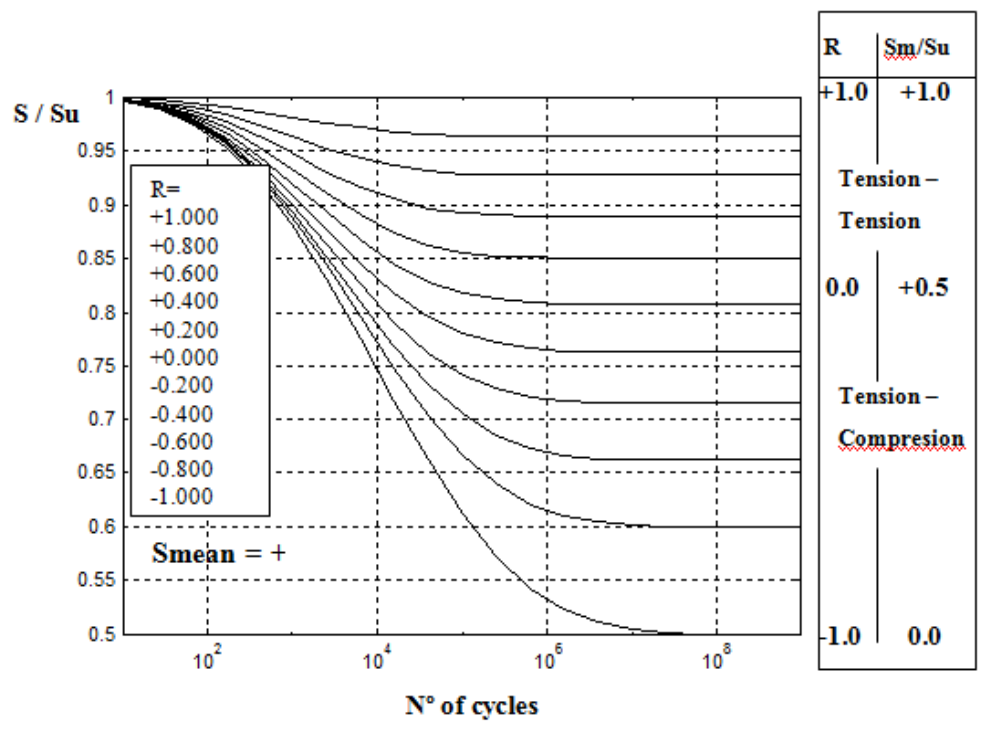

Figure 3: Proposed S - N curves for different values of $R=S_{\min } / S_{\max .}[24]$ 
The proposed $S$ - $N$ curves (equations $12-14$ ) are fatigue life estimators for a material point with a fixed maximum stress and a given ratio $R$. If, after a number of cycles lower than the cycles to failure, the constant amplitude cyclic load with a maximum stress $S_{\max }$ (and ratio $R$ ) is removed, a change in $S_{u}$ is expected due to the accumulation of fatigue cycles. In order to describe that variation of $S_{u}$, the following function is proposed:

$$
f_{\text {red }}\left(R, N_{c}\right)=e^{-B 0 *\left(\log _{10} N_{C}\right)^{B E T A F * B E T A F}}
$$

where $B E T A F$ is one of the parameters of equation 14 and $B 0$ is obtained as a function of the ratio $S_{\max } / S_{u}$ and the number of cycles to failure $N_{f}$ :

$$
B 0=-\frac{\ln \left(S_{\max } / S_{u)}\right.}{\left(\log _{10} N_{f}\right)^{B E T A F * B E T A F}}
$$

The value of $N_{f}$ can be obtained from equation 14

$$
N_{f}=10^{-\frac{1}{B E T A F A L F A T(R)}} \ln \left(\frac{S_{\max }-S_{t h}(R)}{S_{u}-S_{t h}(R)}\right)
$$

Some important observations have to be made regarding the fatigue strength reduction function. Habitually, fatigue models are limited to correctly describing the $S-N$ curves and, based on the level of stress applied, estimate the fatigue life. The $S-N$ curve is generally interpreted as a life prediction tool, meaning that when, for a certain level of stress, the $N_{c}$ corresponding to the Wöhler curve has been reached the respective Gauss point has suffered complete degradation. However, the present model utilizes the respective $N_{c}=N_{f}$ point as the starting point for damage accumulation and the nonlinear zone, for that particular Gauss point. This event mirrors the initiation point for a microcrack. Posterior damage accumulation is an indicator of a rearrangement of the internal structure of the material followed by microfisuration and a completely degraded Gauss point $\left(\mathrm{d}_{\mathrm{GP}}=1\right)$ represents the formation of a macro-crack in the volume associated to the integration point. At macroscale level, a tracking of the damage propagation throughout the continuum is an indicator of a crack propagation and total structural rupture is considered to have occurred when the crack has propagated thru the entire cross-sectional area. The analytical formulation mentioned above has been coupled with a signal processing routine so that random cyclical loading can be decomposed into different load sections, each described by its characteristics: amplitude, reversion factor, number of cycles, period. The residual strength curve quantifies the reduction in material strength due to the application of each loading section in a particular order, as has been shown for metals in [66].

\section{RULE OF MIXTURES}

The serial/parallel mixing theory (SP RoM) is based on the definition of two different compatibility equations between the strain and stress states of the composite constituent materials: it defines an iso-strain condition on the parallel direction, usually the fiber direction, and it defines an iso-stress condition on the serial direction, usually the remaining directions. Using these compatibility equations in a composite made of matrix and fiber, if the matrix structural capacity is lost due to excessive shear stresses, the iso-stress condition also reduces the shear capacity of fiber, and consequently the composite serial strength is also reduced.

For this reason it is necessary to define, and split, the serial and parallel parts of the strain and stress tensors. This is done with two complementary fourth order projector tensors, one corresponding to the serial direction $\left(P_{S}\right)$ and the other to the parallel direction $\left(P_{P}\right)$. These tensors are defined from the fibre axial direction in the composite. Thus,

$$
\varepsilon=\varepsilon_{P}+\varepsilon_{S} \text { with } \varepsilon_{P}=P_{P}: \varepsilon \text { and } \varepsilon_{S}=P_{S}: \varepsilon
$$

where,

$$
P_{S}=I-P_{P} ; P_{P}=N_{P} \otimes N_{P} \text { and } N_{P}=e_{1} \otimes e_{1}
$$


being $e_{1}$, the director vector that determines the parallel behaviour (fibre direction), and $I$ the identity. The stress state may be split analogously, finding its parallel and serial parts using also the 4 th order tensors $P_{P}$ and $P_{S}$

$$
\sigma=\sigma_{P}+\sigma_{S} \text { with } \sigma_{P}=P_{P}: \sigma \text { and } \sigma_{S}=P_{S}: \sigma
$$

\subsection{Hypothesis for the numerical modelling}

The numerical model developed to take into account this strain-stress state is based on the following hypothesis:

1. The composite is composed by only two components: fibre and matrix

2. Component materials have the same strain in parallel (fibre) direction.

3. Component materials have the same stress in serial direction.

4. Composite material response is in direct relation with the volume fractions of compounding materials.

5. Homogeneous distribution of phases is considered in the composite.

6. Perfect bonding between components is also considered.

\subsection{Constitutive equations of component materials}

Each composite component material is computed with its own constitutive equation. However, as in this paper the materials will be modelled with a damage formulation, the description of the formulation is done considering the particular case of isotropic damage. Thus, the stresses in matrix and fibre materials are obtained using

$$
\begin{aligned}
{ }^{m} \sigma & =\left(1-{ }^{m} d\right) \cdot{ }^{m} C:{ }^{m} \varepsilon \\
{ }^{f} \sigma & =\left(1-{ }^{f} d\right) \cdot{ }^{f} C:{ }^{f} \varepsilon
\end{aligned}
$$

being ${ }^{m} C$ and ${ }^{f} C$ the matrix and fibre stiffness tensors, respectively. These equations can be rewritten taking into account the serial and parallel split of strain and stress tensors (equations (19) and (21)), obtaining:

$$
\left[\begin{array}{l}
{ }^{i} \sigma_{P} \\
{ }^{i} \sigma_{S}
\end{array}\right]=\left(1-{ }^{i} d\right) \cdot\left[\begin{array}{ll}
{ }^{i} C_{P P} & { }^{i} C_{P S} \\
{ }^{i} C_{S P} & { }^{i} C_{S S}
\end{array}\right]:\left[\begin{array}{l}
{ }^{i} \varepsilon_{P} \\
{ }^{i} \varepsilon_{S}
\end{array}\right]
$$

where

$$
\begin{array}{ll}
{ }^{i} C_{P P}=P_{P}:{ }^{i} C: P_{P} & { }^{i} C_{P S}=P_{P}:{ }^{i} C: P_{S} \\
{ }^{i} C_{S P}=P_{S}::^{i} C: P_{P} & { }^{i} C_{S S}=P_{S}:{ }^{i} C: P_{S}
\end{array}
$$

\subsection{Equilibrium and compatibility equations}

The equations that define the stress equilibrium and establish the stain compatibility between components arise from the analysis of the hypotheses previously exposed,

$$
\begin{gathered}
\text { Parallel behaviour: } \begin{array}{l}
{ }^{c} \varepsilon_{P}={ }^{f} \varepsilon_{P}={ }^{m} \varepsilon_{P} \\
{ }^{c} \sigma_{P}={ }^{f} k \cdot{ }^{f} \sigma_{P}+{ }^{m} k \cdot{ }^{m} \sigma_{P}
\end{array} \\
\text { Serial behaviour: } \\
{ }^{c} \varepsilon_{S}={ }^{f} k \cdot{ }^{f} \varepsilon_{S}+{ }^{m} k \cdot{ }^{m} \varepsilon_{S} \\
{ }^{c} \sigma_{S}={ }^{f} \sigma_{S}={ }^{m} \sigma_{S}
\end{gathered}
$$

where superscripts $c, m$ and $f$ stand for composite, matrix and fibre, respectively and ${ }^{i} k$ corresponds to the volume fraction coefficient of each constituent in the composite. 


\subsection{Serial/parallel rule of mixtures algorithm}

The known variable that enters the algorithm is the strain state ${ }^{c} \varepsilon$ of the composite material at time $t+\Delta t$. From this variable, the serial/parallel rule of mixtures algorithm has to find the strain and stress state of each component that fulfils the equilibrium, the compatibility and the constitutive equations and the evolution of the internal variables. The first thing done by the algorithm is to split the strain tensor into its parallel and its serial parts, in order to compute the strain state in the matrix and the fiber. The parallel strain component is, according to equation (25), the same for both materials and for the composite. On the other hand, the serial strain component requires a prediction of the strains expected in one of the composite components. If this prediction is done for the matrix, the increment of its serial strains can be computed as

$$
\left[{ }^{m} \Delta \varepsilon_{S}\right]^{0}=A:\left[{ }^{f} C_{S S}:{ }^{c} \Delta \varepsilon_{S}+{ }^{f} k \cdot\left({ }^{f} C_{S P}-{ }^{m} C_{S P}\right){ }^{c} \Delta \varepsilon_{P}\right]
$$

with $A=\left[{ }^{m} k \cdot{ }^{f} C_{S S}+{ }^{f} k \cdot{ }^{m} C_{S S}\right]^{-1}$ and ${ }^{m} \Delta \varepsilon_{S}={ }^{t+\Delta t}\left[{ }^{c} \varepsilon_{S}\right]{ }^{t}\left[{ }^{c} \varepsilon_{S}\right]$.

The initial prediction of matrix serial strains, proposed by Rastellini [67] and described in equation (27), is obtained considering that the distribution of the total strain, in its parallel and serial parts, is done in function of the composite tangent stiffness obtained in previous time step. With the prediction of the matrix serial strains, the fibre serial strains can be computed, in the iteration step $n$, according to equation (26),

$$
{ }^{t+\Delta t}\left[{ }^{f} \Delta \varepsilon_{S}\right]^{n}=\frac{1}{f} k^{t+\Delta t}\left[{ }^{c} \varepsilon_{S}\right]-{\frac{{ }^{m} k}{{ }^{f} k}}^{t+\Delta t}\left[{ }^{m} \varepsilon_{S}\right]^{n}
$$

where ${ }^{t+\Delta t}\left[{ }^{m} \varepsilon_{S}\right]^{n}={ }^{t}\left[{ }^{m} \varepsilon_{S}\right]+\left[{ }^{m} \Delta \varepsilon_{S}\right]^{n}$.

Regrouping again the serial and parallel components of the strain tensor (equation (21)), the constitutive equations can be applied to the predicted strains to obtain the stress tensor for both materials and the update of their internal variables. Fibre and matrix are modelled, each one, with their own constitutive law. If both materials are described with an additive plasticity formulation, the stress vector for each one is obtained using equation (22). The stresses obtained must fulfil the following equation:

$$
\left[\Delta \sigma_{S}\right]^{n}={ }^{t+\Delta t}\left[{ }^{m} \sigma_{S}\right]^{n}-{ }^{t+\Delta t}\left[{ }^{f} \sigma_{S}\right]^{n} \leq \text { toler }
$$

If the residual stress is smaller than the tolerance, the computed strains and stresses are considered to be correct and the structural calculation can continue. However, if equation (29) is not fulfilled, the initial prediction of the matrix strain tensor has to be corrected. This correction is performed using a NewtonRaphson scheme, in which the update is made using the Jacobian of the residual forces. It is obtained deriving the residue function with respect to the unknown. According to Rastellini [68], the expression for the Jacobian is given as follows:

$$
J=\left[{ }^{m} C_{S S}^{t}\right]^{n}+\frac{{ }^{m} k}{{ }^{f} k} \cdot\left[{ }^{f} C_{S S}^{t}\right]^{n}
$$

and the correction of the matrix serial strains becomes

$$
{ }^{t+\Delta t}\left[{ }^{m} \varepsilon_{S}\right]^{n+1}={ }^{t+\Delta t}\left[{ }^{m} \varepsilon_{S}\right]^{n}-J^{-1}:\left[\Delta \sigma_{S}\right]^{n}
$$

To obtain quadratic convergence in the S/P mixing theory, the Jacobian must be obtained using the tangent constitutive tensors for the fibres and the matrix. Depending on the constitutive equation defined for each material, the constitutive tensor cannot be obtained analytically. Thus, in order to obtain a reliable algorithm, the expression of the tangent tensor is obtained numerically with the procedure shown by Martinez et al. [22][23].

\section{STEPWISE LOAD ADVANCING STRATEGY}

\subsection{Introduction}

The constitutive formulation described in Section 2 is coupled with a stepwise load-advancing strategy 11 
described in Oller et al. [24] and Barbu et al.[21] that consists of two different phases. The first one is defined by load-advance being conducted by small time increments, with the consequent load variation following a cyclic path. The second phase is characterized by load-advance being done with large increments of number of cycles. The strategy consists of an algorithm that automatically switches from one phase to the other, going repeatedly back and forth between both in accordance with the loading input and the damage increase rate.

\subsection{Load-tracking phase}

This phase is characterized by the load being applied in small increments. The purpose is to determine and save the characteristics of the cyclical load. The tags $A i$ referenced in the following can be seen in the flow chart for this phase, on the left side of Figure 4.

Each load cycle will be divided into $m$ small steps, a value that is user defined. At the beginning of each increment being conducted in this phase, both the load factor and the number of cycles will be updated (see A1 in Figure 4). Based on the multiaxial stress state, the equivalent stress will be computed according to the damage criterion chosen (von Mises, Mohr-Coulomb, Tresca, Drucker-Prager). After that, the difference between the equivalent stress $f^{D}\left(S_{i j}\right)$ of current increment $k$ and previous increment $k-1$ will be compared to the difference between the equivalent stress in $k-1$ with respect to $k-2$ (A2). When the sign of these two quantities is different, either a maximum or a minimum has been recorded in increment $k-1$ (A3). After having detected both the maximum and the minimum equivalent stress for each integration point, the reversion factor is computed, $R=S_{\min } / S_{\max }$. After each new cycle $i+1$ is described, the reversion factor is compared to its value in the previous cycle $i$. The normalized variation of the reversion factor is evaluated for each integration point $G P$ and the sum of all the variations detected is computed into a stabilization norm $\eta$ as shown in the following equation (A4):

$$
\eta=\sum_{G P}\left|\frac{R_{G P}^{i+1}-R_{G P}^{i}}{R_{G P}^{i+1}}\right| \leq \text { toler }
$$

A new value for $f_{\text {red }}\left(N, S_{\max }, R\right)$ is computed and the equivalent stress is then affected by it and compared to the damage strength threshold in the current increment (A5). The global convergence is checked and, if this is achieved, then the stabilization norm is compared to a user defined tolerance. When this norm is below a given tolerance, it can be said that the reversion factor has a stable value throughout the solid (A6). A flag is then activated indicating that in the next increment the large phase algorithm should be followed. If the value of $\eta$ is not below the tolerance, several more cycles are then analysed applying small increments.

This phase is necessary at the beginning of each different cyclical load in order to determine the parameters that define the cyclic behaviour at each Gauss point of the structure ( $R$ and $\left.S_{\max }\right)$. Therefore, in case of modifying the cyclic load, a new activation is necessary.

\subsection{Large increments phase}

After the stress parameters, $R$ and $S_{\max }$, stabilize throughout the solid from one cycle to the other, there is no need to keep applying small increments as there will be no change in the stress state unless either the elastic threshold is reached or the applied cyclical load changes. Therefore, the load level can be maintained at its maximum value and large number of cycles increments can be applied. The tags $B i$ referenced in the following can be seen in the flow chart for this phase, on the right side of Figure 4.

In this phase, the variable is not the level of the load, kept constant at its maximum value, but the number of cycles, which, in each increment, is updated with a new large $N c$ step (B1). After obtaining the equivalent stress, a new value for $f_{\text {red }}\left(N, S_{\max }, R\right)$ is computed directly with the current number of cycles and the previously stored values for $R$ and $S_{\max }$ (B2). The equivalent stress affected by $f_{\text {red }}\left(N, S_{\max }, R\right)$ is then compared with the current damage strength threshold. If nonlinear behaviour occurs at at least one 
integration point a flag is activated (B3). When global convergence of the problem has been obtained in the current increment and the flag has been activated inside the constitutive loop, the next increment will be conducted with the load-tracking algorithm (B4).If convergence has been reached but the flag was not activated, in the next increment another large step will be applied.

\subsection{Automatic load-tracking phase activation}

The stepwise advancing strategy has the following implications:

When applying a single cyclical load, load advance will be done by passing initially through the loadtracking phase until $R$ stabilizes and $\eta$ is lower than the defined tolerance. Afterwards, the advancing scheme will be by the number of cycles until reaching the elastic threshold for the first composite component. This is when the material has been subjected to the number of cycles indicated by the S-N curve for this component. At this stage, the internal forces of the structure are modified in order to reach a new equilibrium configuration. This situation leads to a variation of the reversion factor and, therefore, of the stress state at integration point level. The load-tracking phase is automatically activated. Furthermore, it will be activated at each step where damage increases $(\dot{d}>0)$ due to the change in internal forces.

The algorithm can be optimized if, after evaluating the Wöhler's $N f$ (marked dot in Figure 2) corresponding to each equivalent stress level at the beginning of the analysis, a search is made to find the minimum fatigue life throughout the solid. The resulting number of cycles can be used as the first step of the large increments phase ensuring that the entire span of number of cycles before the damage process initiates is done in one step (B1)(See Figure 4). The nonlinear processes occurring past the point damage initiates in the first Gauss point will be simulated with a user-defined $N_{c}$ step in the case of displacement controlled simulations where the material can continue bearing the cyclical load after having reached the fatigue life given by the S-N curve. This is possible due to a progressive loss of stiffness that ensures that, for the same applied cyclical displacement and having reached the S-N curve, stress in the material progressively relaxes as it suffers damage until total rupture.

In the case of applying different cyclic loads, damage can appear either due to fatigue or due to a new load being applied that leads to stress values that surpass the elastic threshold. In both cases the model will jump automatically from the large increments phase to the load-tracking phase. Even if the different cyclic loads applied induce stress levels below the elastic threshold, when passing from one cyclic load to another one of different characteristics an activation of the load-tracking is required. This is necessary regardless of the elastic regime due to the fact that, by applying a new load, the maximum equivalent stress induced and/or the reversion factor has changed and, consequently, the fatigue parameters calculated for the first load are no longer valid.

The flow chart presented in Figure 4 shows the operations conducted in both phases, as well as the conditions required to jump from load-tracking to large increments. These jumps are indicated with hyphenated arrows.

The algorithm is user controlled by means of two parameters. The first one is the tolerance at which the reversion factor norm (defined in section 4.2.) is considered to have converged. If, for instance, a numerical tolerance of $10^{-10}$ is used, time advance runs the risk of being continually conducted in the load-tracking phase. This would lead to a dramatic increase in computational time. On the other hand, if the tolerance is set too high the model may no longer capture changes in the cyclical load applied, leading to an incorrect life prediction. The tolerance used for the calculation of the numerical examples presented in section 4 was $10^{-4}$ and the authors recommend this value for future use of the strategy.

The second parameter that allows the user to control the developed stepwise load advancing algorithm is the number of cycles chosen as time step for the large increments phase. The influence it has is in accordance with the level on nonlinearity of the problem. While a too low number of cycles step implies an increase in computational time, a too big one can lead to loss of solution convergence.

A calibration analysis consisting of a study of the solution convergence depending on the number of cycles step is highly recommended. The analysis should begin by using large steps. Then the $N_{c}$ used as a step should be progressively lowered until convergence is reached, as this would ensure the lowest computational time. 


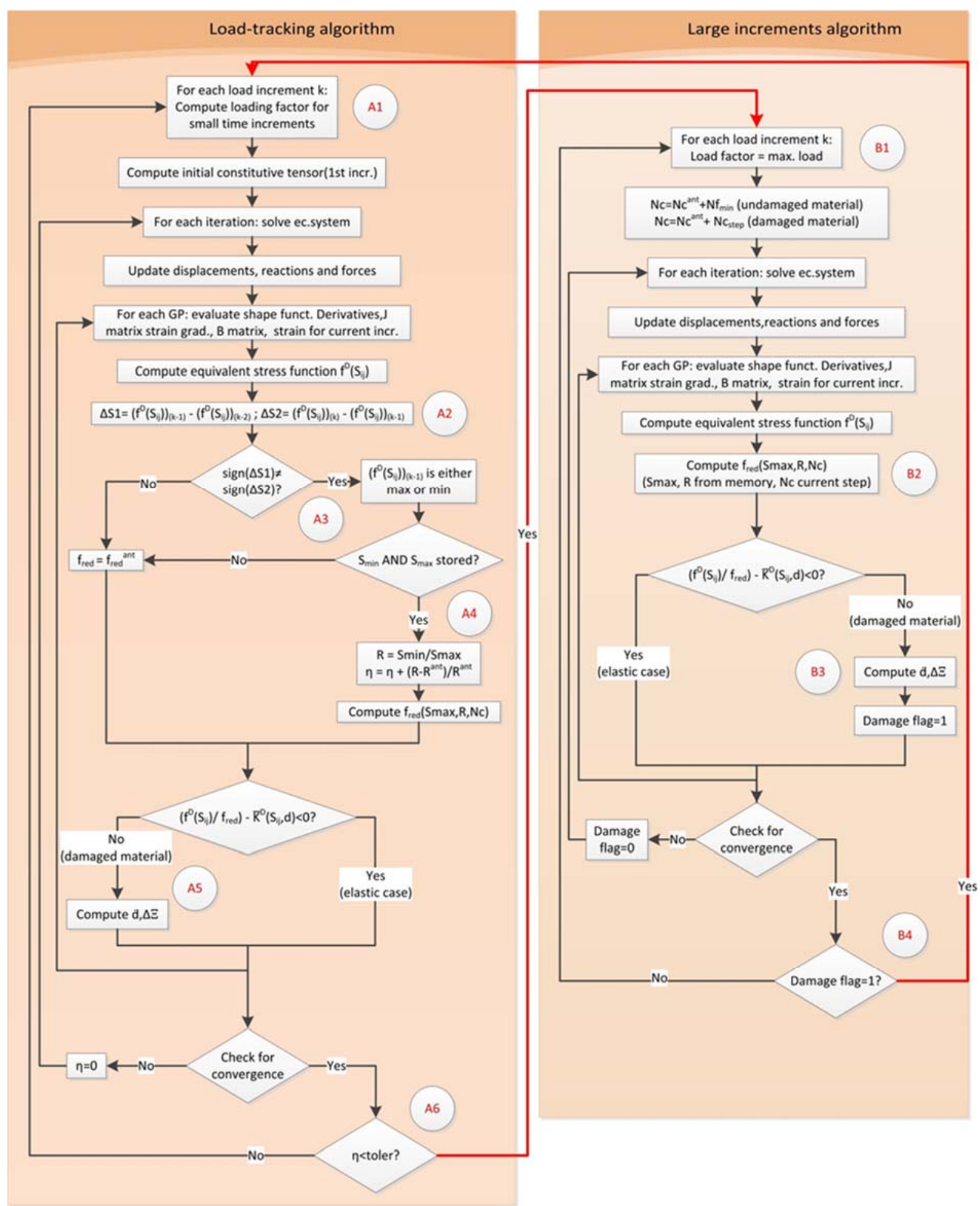

Figure 4: Flow chart for the stepwise advancing algorithm

\section{FATIGUE NUMERICAL SIMULATION OF PULTRUDED GLASS FIBER REINFORCED POLYMER PROFILE}

The capabilities of the fatigue constitutive model, together with the stepwise load-advancing strategy presented, will be shown by comparing results obtained from numerical simulations with the results provided in the experimental work presented in Keller et al. [69] .

All the examples presented in this section have been calculated with the PLCd finite element code, where the formulation presented here has been implemented. A more detailed description of the code and 
its fatigue and composites capabilities can be obtained from references [70] to [76].

\subsection{Problem definition. Geometry and material.}

Pultruded GFRP plate profiles with $100 \times 5 \mathrm{~mm}$ rectangular cross-section were examined. The plates consist of E-glass fibers embedded in an isophthalic polyester resin. The fiber architecture comprised mainly unidirectional rovings in the central region and one combined mat in the outside regions [77]. The combined mats consist of chopped strand mats (CSM) and woven mats $0^{\circ} / 90^{\circ}$ of different weights; these two mats are stitched together. Furthermore, a polyester surface veil $(40 \mathrm{~g} / \mathrm{m} 2)$ was added. The corresponding experimental fiber fractions are listed in Table 1. They were determined by weighing the specimen before and after a resin burn-off in a furnace at $450{ }^{\circ} \mathrm{C}$. The experimental volume fractions were calculated using an E-glass density of $2.56 \mathrm{~g} / \mathrm{cm} 3$. Since the fatigue behaviour is influenced by internal material defects and voids, some cross-sections were investigated by means of microscopy. The analysis showed a very good embedment of the fibers without any voids [77].

\begin{tabular}{|c|c|c|c|}
\hline \multirow[t]{2}{*}{ Reinforcement } & \multicolumn{3}{|l|}{ Profiles $100 \times 5 \mathrm{~mm}$} \\
\hline & Architecture & $\%$ by volume & $\%$ by weight \\
\hline Rovings (UD) & 4:1 Straight and blown & 37 & 53 \\
\hline Combined mats: & $2 \times 1$ & & \\
\hline $\operatorname{CSM}\left(\mathrm{g} / \mathrm{m}^{2}\right)$ & 300 & 5 & 7 \\
\hline woven $0^{\circ} / 90^{\circ}$ & $150 / 150$ & 5 & 7 \\
\hline Total & & 47 & 67 \\
\hline
\end{tabular}

Table 1. Fiber architecture and fractions by volume and weight of the pultruded profiles used [69]

The specimen shape used was a tapered form (TP specimens, dog-bone shape) presented in Figure 5. They were cut with a water-jet into a dog-bone form according to ASTM E 466-96 with a gage length of $300 \mathrm{~mm}$, a gage width of $40 \mathrm{~mm}$ and, accordingly, a grip-to-gage width ratio of 2.5. The radius of curvature between the ends was $390 \mathrm{~mm}$. The TP specimens were left in a laboratory environment for more than one week prior to testing to reduce the moisture effects induced during the cutting process [69].

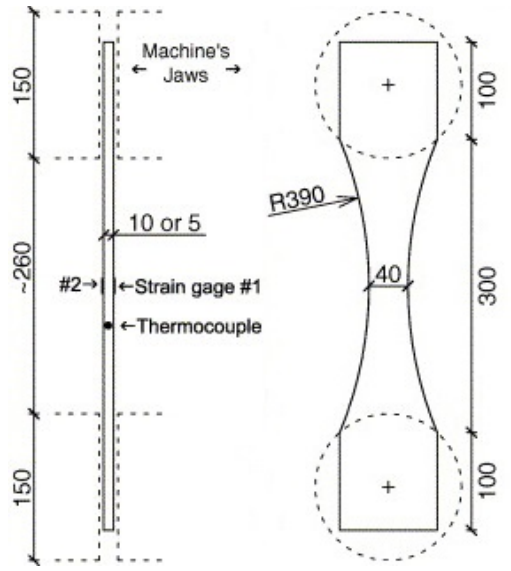

Figure 5. Experiment specimen with strain and temperature gages [69]

\subsection{Finite element model}

The fatigue test specimen presented in Figure 5 has been discretized by means of a finite element model. The dog-bone shape volume has been meshed with quadratic hexahedral elements as shown in Figure 6. The mesh has 13896 nodes and 2354 elements. Each finite element is described with 27 integration points. 


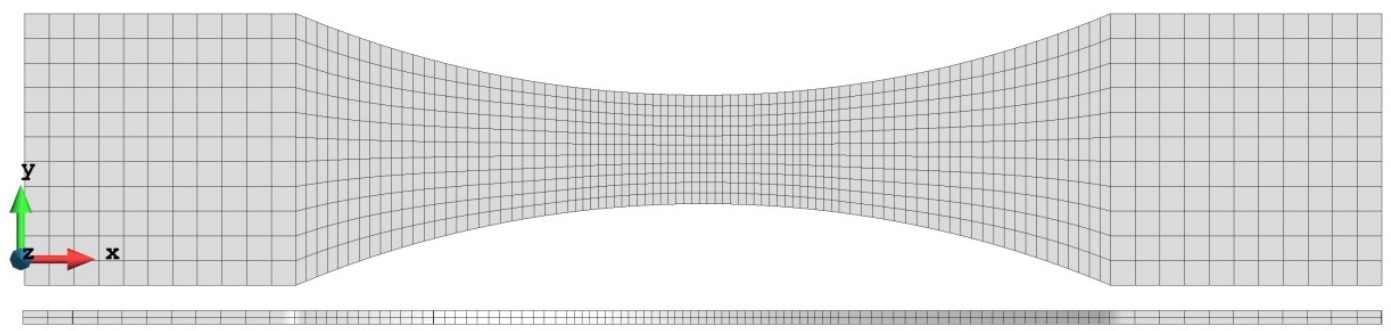

Figure 6. Finite element mesh of quadratic hexahedral elements

The applied boundary conditions are shown in Figure 7. The specimen is restrained at one end and subjected to a cyclical displacement at the other end. All numerical simulations have been conducted under displacement-controlled conditions.

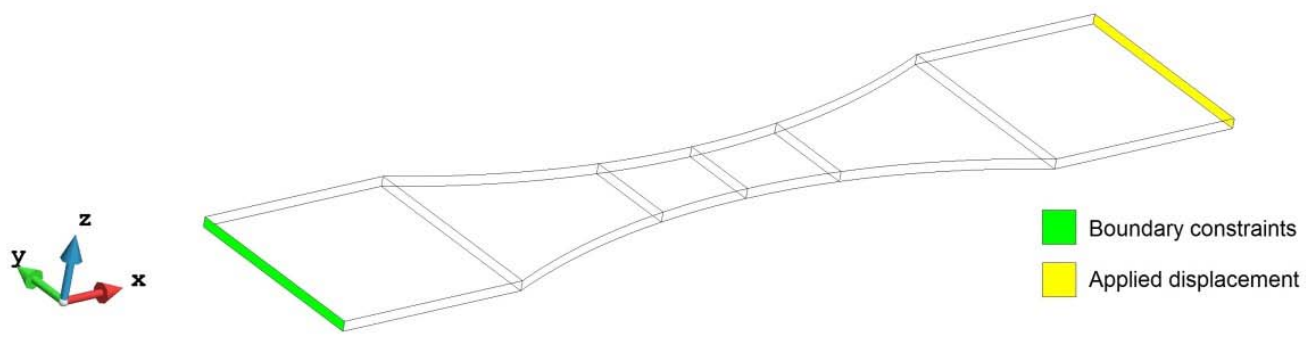

Figure 7. Boundary and loading conditions for the analysed geometry

The analytical formulation for the S-N curve used by the numerical model was the one presented in [24]. A decomposition of the experimental S-N curve of the composite found in Keller et al. [69] has been made. The maximum composite stress for each experimental test has been decomposed according to the volumetric participation of each component into a maximum associated stress in the matrix and a maximum associated stress in the fiber. Using this decomposition associated artificial S-N points have resulted for the matrix and fiber as derived from the experimental composite S-N curve. This is necessary because the formulation is based on component S-N curves. Thus, for each experimental point of the composite an experimental point is derived for the matrix and one for the fiber using equation (25).

Afterwards, a calibration process has been conducted for both the fiber and the matrix in order to find the material parameters that approximate correctly the family of S-N curves for each of them, in accordance to the experimental points derived earlier. We are referring to the S-N curves as a family because the material parameters that are necessary for the calibration describe an entire range of reversion factors with different mean stress values. A calibration process is necessary to ensure that the analytical curves used by the model at each integration point and each component are in accordance with the experimental results on fiber and matrix and the precision of the calibration is directly dependent on the number of results available. An extensive experimental campaign where different $R$ factors are used and many different mean stress values tested would be ideal as this would ensure that the calibration is more precise and can be verified extensively. In this case the material parameters have been chosen so that the numerical S-N curve is well adjusted to the experimental points considered after the decomposition for the data shown by [69]. The parameters used for the adjustment of the numerical S-N curve to the experimental one proposed by Keller et al. [69] are $\mathrm{Se} / \mathrm{Su}=0.1, \mathrm{STHR} 1=1.5, \mathrm{STHR} 2=1.5, \mathrm{ALFAF}=0.01, \mathrm{AUXR} 1=0.0001$ and $\mathrm{AUXR} 2=0.008$, $\mathrm{BETAF}=3.1$ for the matrix and $\mathrm{Se} / \mathrm{Su}=0.01, \mathrm{STHR} 1=3, \mathrm{STHR} 2=1.5, \mathrm{ALFAF}=0.135, \mathrm{AUXR} 1=0.0001$ and AUXR2 $=0.008, \mathrm{BETAF}=1.68$ for the fiber. The S-N curves obtained with the above parameters are shown in Figure 8 for the matrix and in Figure 9 for the fiber. 


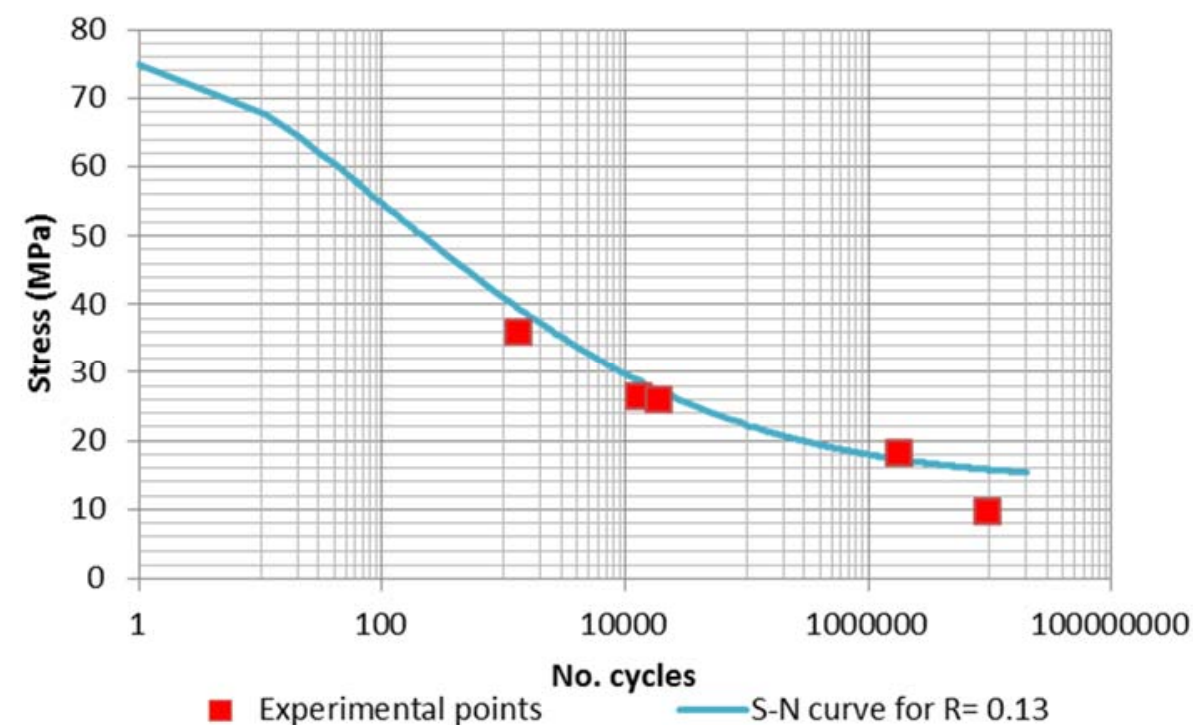

Figure 8. Artificially derived S-N curve for the isophtalic matrix

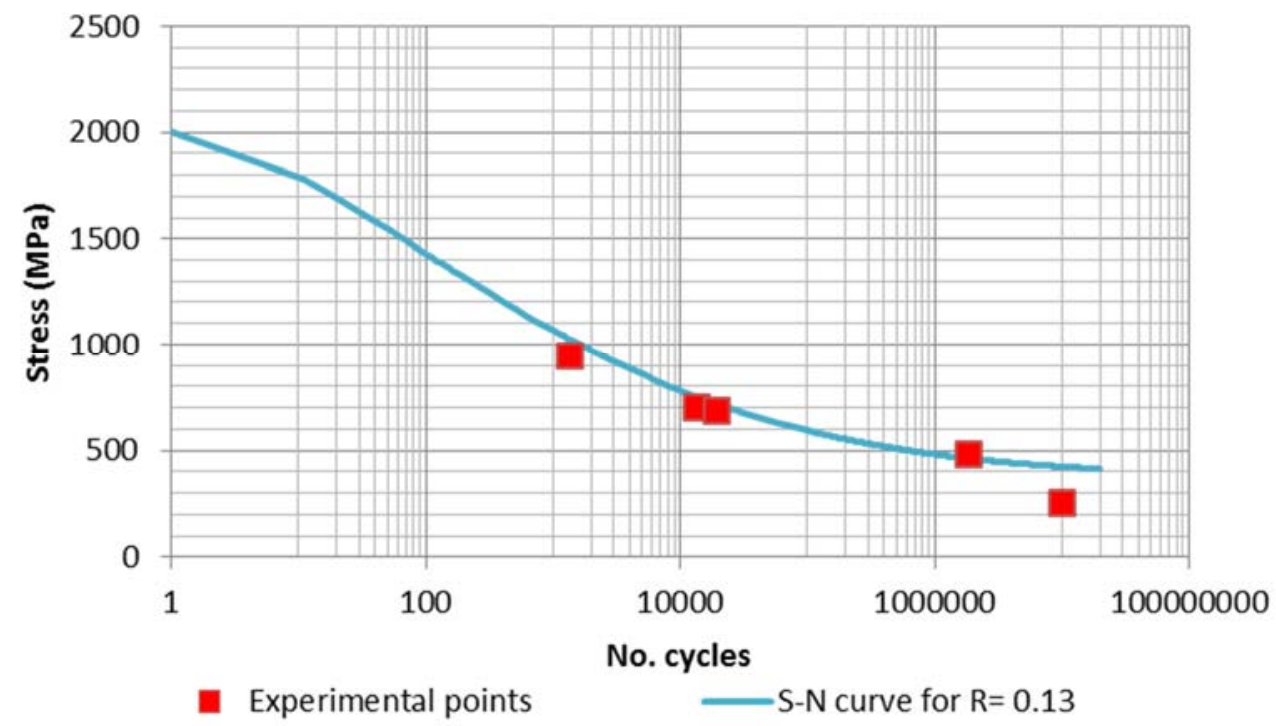

Figure 9. Artificially derived S-N curve for the glass fibers

The material properties used in the numerical simulations are shown in Table 2.

\begin{tabular}{c|cccc} 
Component & $\begin{array}{c}\text { Ultimate limit } \\
\text { strength UTS }(\mathrm{MPa})\end{array}$ & $\begin{array}{c}\text { E-Modulus } \\
\text { longitudinal }(\mathrm{GPa})\end{array}$ & $\begin{array}{c}\text { E-Modulus } \\
\text { transversal }(\mathrm{GPa})\end{array}$ & $\begin{array}{c}\text { Fracture energy } \\
(\mathrm{MN} \cdot \mathrm{m} / \mathrm{m} 2)\end{array}$ \\
\hline Fiber & 2000 & 78.5 & 3 & 500 \\
Matrix & 75 & 3 & 3 & 10
\end{tabular}

Table 2. Material properties used in the numerical simulations

The values used for the elastic parameters are average values for these two specific components and they have been taken from [78]. The fracture energy of the fiber and matrix has been calibrated so that the same fatigue life was to be obtained in the numerical simulation as in the experimental program for one of the cases. The rest of the simulations were done using these values as material properties as can be seen in Table 2. It is important to note that for the glass fibers the same transversal modulus has been assumed as for the matrix. This is necessary in order to facilitate the convergence of the SP RoM when advanced 
nonlinearity appears in both the fiber and the matrix.

\subsection{Experimental program}

The experiments were performed in a laboratory environment at room temperature without humidity control. Effects of environmental exposures (temperature, moisture, chemicals) on the fatigue behavior were not investigated.

First, single-cycle axial tension experiments were performed with displacement-controlled loading at a rate of $0.6 \mathrm{~mm} / \mathrm{min}$ up to failure. The numbers of experiments per specimen shape are listed in Table 3 .

\begin{tabular}{c|ccc} 
Specimen & Ultimate limit strength UTS (MPa) & Failure strain (\%) & E-Modulus (MPa) \\
\hline $5 \mathrm{~mm}$ tapered & $459 \pm 24$ & $1.37 \pm 0.07$ & $34,799 \pm 584$
\end{tabular}

(3 specimens)

Table 3. Composite properties as recorded from the static experimental tests[69]

Subsequently, cyclic axial tension-tension experiments were conducted load-controlled with a sinusoidal waveform of constant amplitude. The specimens were loaded at a minimum to maximum load ratio of $\mathrm{R}=0.1$ and at different loading ranges. The upper boundary values were varied from $20 \%$ up to $80 \%$ of the average ultimate tension strength (UTS) of the static experiments (see Table 3). Experiments were performed up to specimen failure (separation of samples) or up to ten million load cycles at maximum (if possible due to time constraints). The parameter combinations used in this study are summarized in Table 4.

\begin{tabular}{|c|c|c|c|c|c|c|c|}
\hline Series & Specimen & $\begin{array}{l}\text { Loading } \\
\text { range } \\
\Delta \mathrm{F} \\
(\mathrm{kN})\end{array}$ & $\begin{array}{l}\text { Stress } \\
\text { range } \\
\Delta \sigma \\
\text { (MPa) }\end{array}$ & $\begin{array}{l}\text { Maximum/ } \\
\text { ultimate } \\
\text { load (\%) }\end{array}$ & $\begin{array}{l}\text { Amplitude } \\
\text { ratio } R\end{array}$ & $\begin{array}{l}\text { Cycles to } \\
\text { failure } N_{\mathrm{f}}\end{array}$ & Remarks \\
\hline \multirow{5}{*}{$\begin{array}{l}5 \mathrm{~mm} \\
\text { tapered }\end{array}$} & TP5-1 & 65 & 325 & 82 & 0.13 & 1346 & \\
\hline & ТР5-2 & 48 & 240 & 60 & 0.13 & 13,407 & \\
\hline & TP5-3 & 47 & 235 & 59 & 0.13 & 19,159 & \\
\hline & TP5-4 & 33 & 165 & 41 & 0.13 & $1,875,940$ & \\
\hline & ТP5-5 & 17 & 85 & 22 & 0.15 & $5,000,000$ & $\begin{array}{l}\text { not } \\
\text { failed }\end{array}$ \\
\hline
\end{tabular}

Table 4. Overview of experimental results [69]

\subsection{Results and discussion}

The simulation program started with a trial static simulation in order to confirm that the volumetric participations used in the numerical simulations yielded the same initial stiffness as the experimental results. The experimental stresses shown in Table 3 were calculated from the measured loads (average stress in the cross-section); the strains were obtained from the average measurements from strain gages 1 and 2 (see Figure 5). Due to the experimental fiber architecture of the specimen (detailed in Table 1) the first combination of volumetric participations tested was $42 \%$ fibers and $58 \%$ matrix. These values have been chosen in order to approximate the contribution of the two combined mats consisting of chopped strand mats (CSM) and woven mats $0^{\circ} / 90^{\circ}$ of different weights. In the numerical simulation these mats were not specifically discretized as a different material. Therefore, by increasing the volumetric participation of the fibers with respect to the UD rovings, their effect was to be taken into account in a homogenized way. Even though the two combined mats increased the volumetric fiber participation by $10 \%$, only a $5 \%$ increase has been considered numerically since it was considered that the longitudinal contribution of the mats were of only 5\%, an assumption made by Keller et al. [69]. However, it can be seen from Figure 10 that the initial stiffness obtained in the numerical simulation with this volumetric participation is not in accordance with 
the experimental recordings ( $14.65 \%$ error in strain for a stress level of $400 \mathrm{Mpa})$. The next fiber percentage tested was $37 \%$, the percentage experimental recordings showed to correspond to the UD rovings. For this percentage the error was of only $3,76 \%$ for the same stress level and this was considered acceptable.

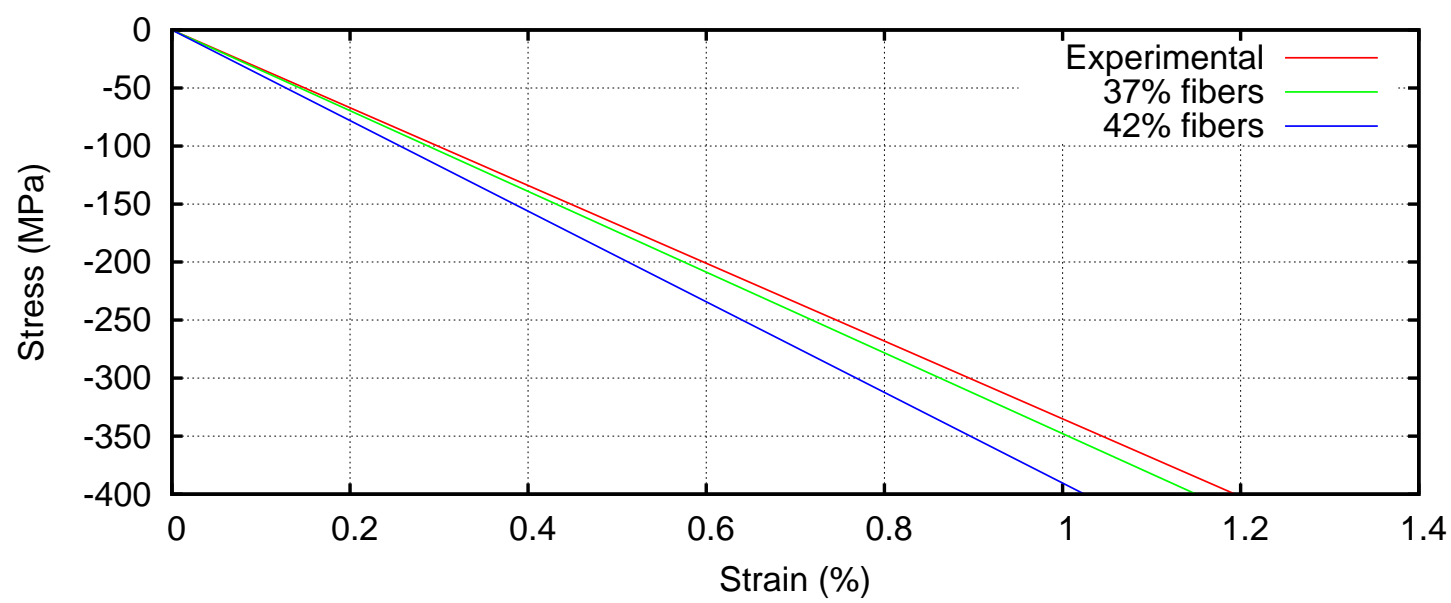

Figure 10. Initial stiffness for the static case. Comparison between experimental and numerical values.

Following, cyclic loading simulations have been ran with an applied cyclic displacement that induced the same stress amplitude and maximum stress as the experimental recordings in Table 4. From these simulations two aspects are analysed in detail: the failure mode and the number of cycles until failure.

\subsubsection{Failure mode}

Some considerations have to be made with respect to the experimental failure mode. The static tests showed that the stress-strain relationship of the profiles was almost linear-elastic up to failure. Failure always occurred in a very brittle and sudden manner without any visible or audible signs (such as surface cracks or cracking noises). Therefore, it could not be determined where the fracture initiated. The specimens showed principally one diagonal crack in the tapered region and some small longitudinal cracks in the grip region (see Figure 11 ) and they were split-up in the profile plane mainly between the outer layers containing the combined mats and the center part containing the UD-rovings. The length of the split parts spanned, more or less, the beginning and the end of the diagonal cracks and the whole profile widths. The center parts were split-up themselves along bundles of UD-rovings and resin. The diagonal cracks formed principally in the outer layers containing the combined mats. The fiber failures of the UD-rovings were distributed longitudinally in the split-up parts and were not concentrated in the diagonal cracks. All of the UD-roving fibers must have been failed within the split-up parts since no further load could be applied.
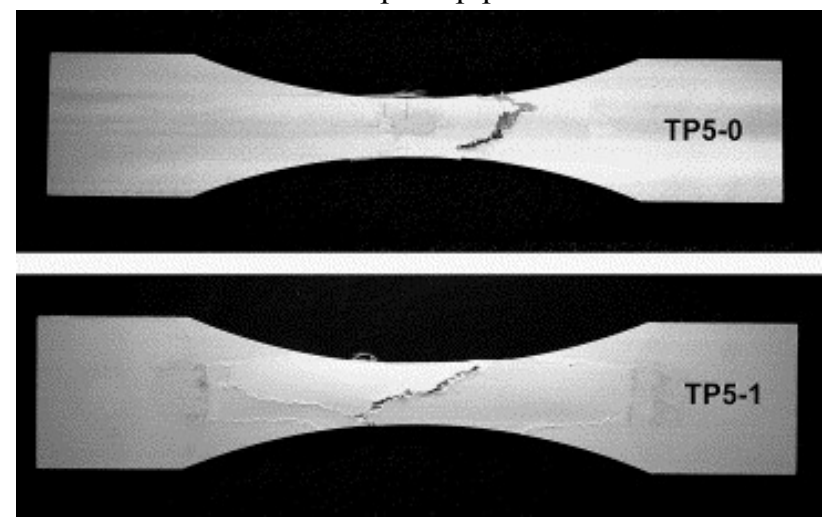

Figure 11. Static (above) and fatigue (below) experimental failure modes

During the fatigue tests, 4 specimens fractured while one specimen did not fail, as can be seen in Table 4. The failure modes under fatigue loadings were basically identical to the failure modes under quasi-static loadings (see Figure 11). In several specimens, however, the widths of the cracks in the outer profile layers 
and the total elongations of the specimens were much more significant in the fatigue experiments compared to the static experiments. This observation can be explained by the progressive deterioration of the matrix and fiber/matrix interfaces, which led to easier pull out of the failed fibers [69].

The failure mode obtained in the numerical simulations can be seen in Figure 12 for one of the numerical simulations. Specifically this simulation was set to run with the same characteristics as specimen TP5-1 in Table 4. The diagonal distribution of the cracks was not found in any of the numerical simulations. A possible reason is that the combined mats where the diagonal experimental cracks were located were not taken into account in the numerical simulation.

In the numerical simulation the specimen lasted a total of 1311.08 cycles until failure. The distribution of the damage parameter for the composite material is shown at different time steps. It can be seen that damage initiates in the numerical simulation in the exterior parts of the curvature. As the number of cycles applied increases, the internal damage variable continues to increase in those same areas and consequently stress redistribution occurs in the material. This stress redistribution activates the central area of the specimen where damage starts to accumulate also, cutting through the cross sectional area of the specimen, perpendicular to its longitudinal axis. It should be noted that in the numerical simulation the failure mode is symmetric. Damage propagation in the width of the specimen occurred mainly in the two last cycles of the simulation, indicating that the failure mode in the numerical model was also brittle, same as in the experiment.
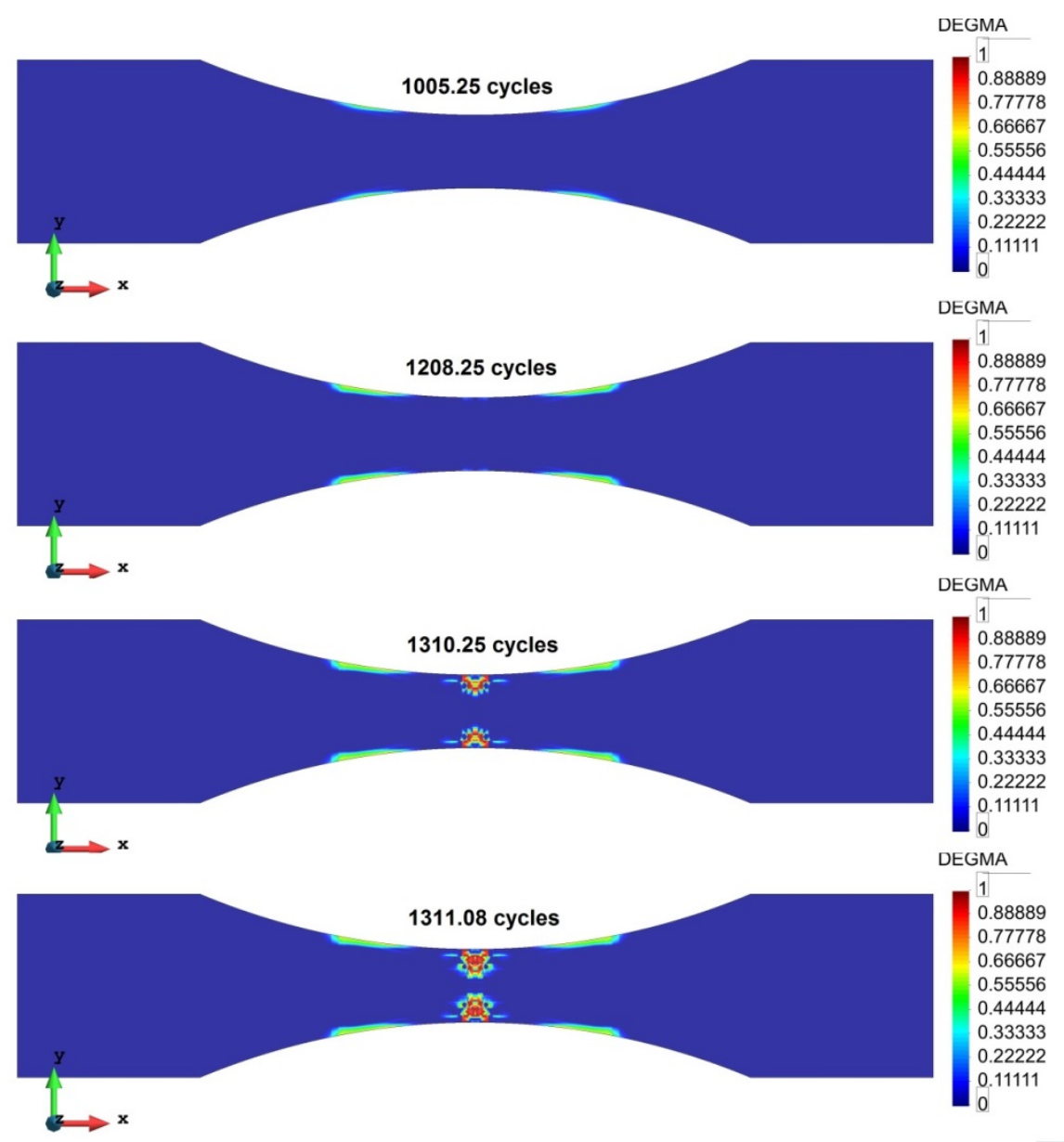

Figure 12. Distribution of the damage internal variable for the composite at different time steps

Figure 13 shows the evolution of the damage parameter in the glass fibers. It can be seen that while damage is located in the exterior area of the curvature the fibers remain in an elastic state. Only after approximately 1200 cycles the fibers in the central area of the model start to enter into the nonlinear domain 
due to the reduction in strength caused by the reduction coefficient, $f_{\text {red }}\left(N, S_{\max }, R\right)$, propagating through the width of the specimen mostly in the last two cycles of the simulation. In Figure 14, it can be seen that damage in the external areas of the specimen curvature appears due to matrix degradation. However, only the matrix cracking is not enough to lead to specimen failure. Only when fiber degradation occurs failure is reached and this happens due to cross sectional degradation until the remaining area cannot bear the applied cyclic loading.

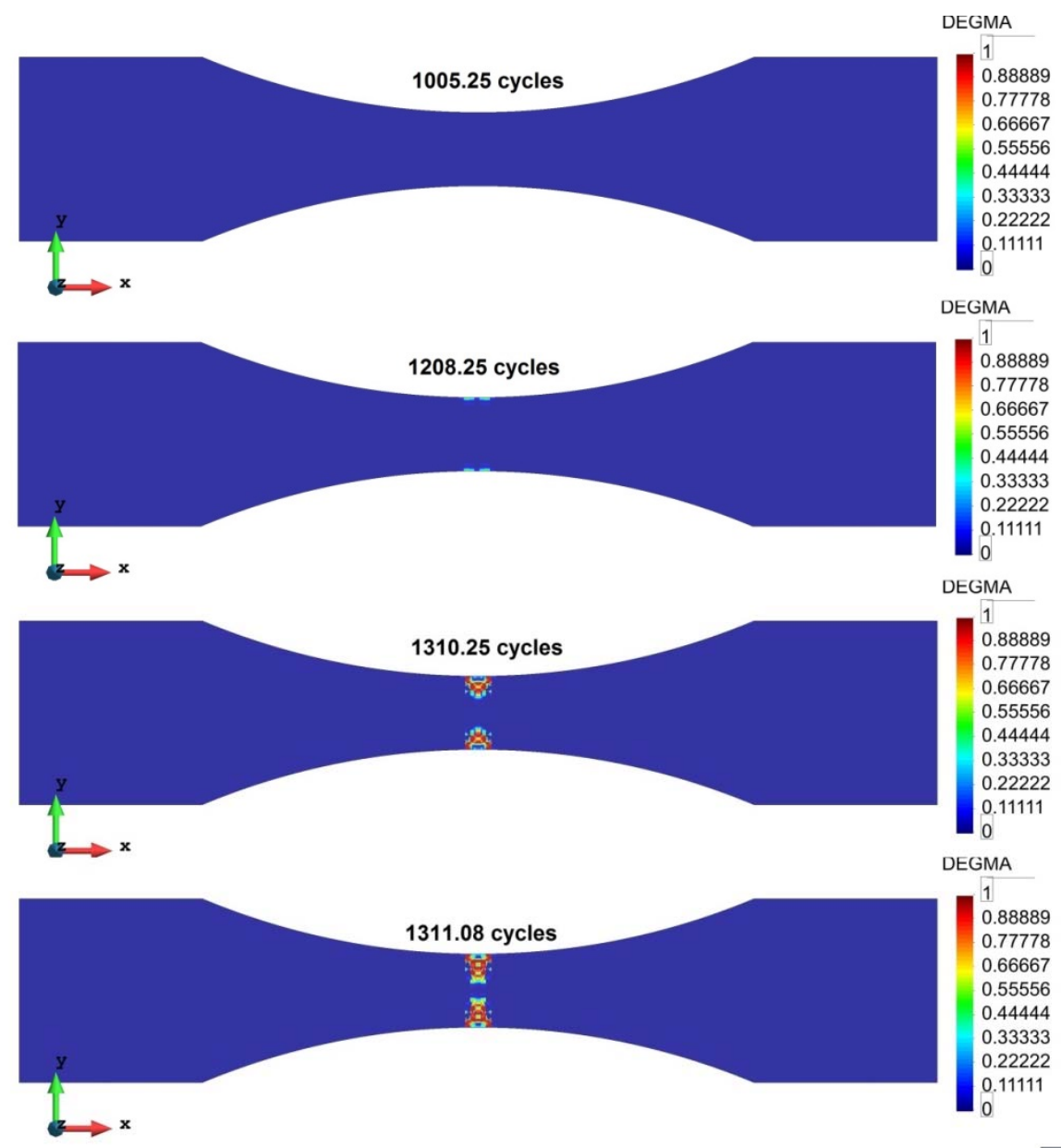

Figure 13. Distribution of the damage parameter in the glass fibers at different time steps 


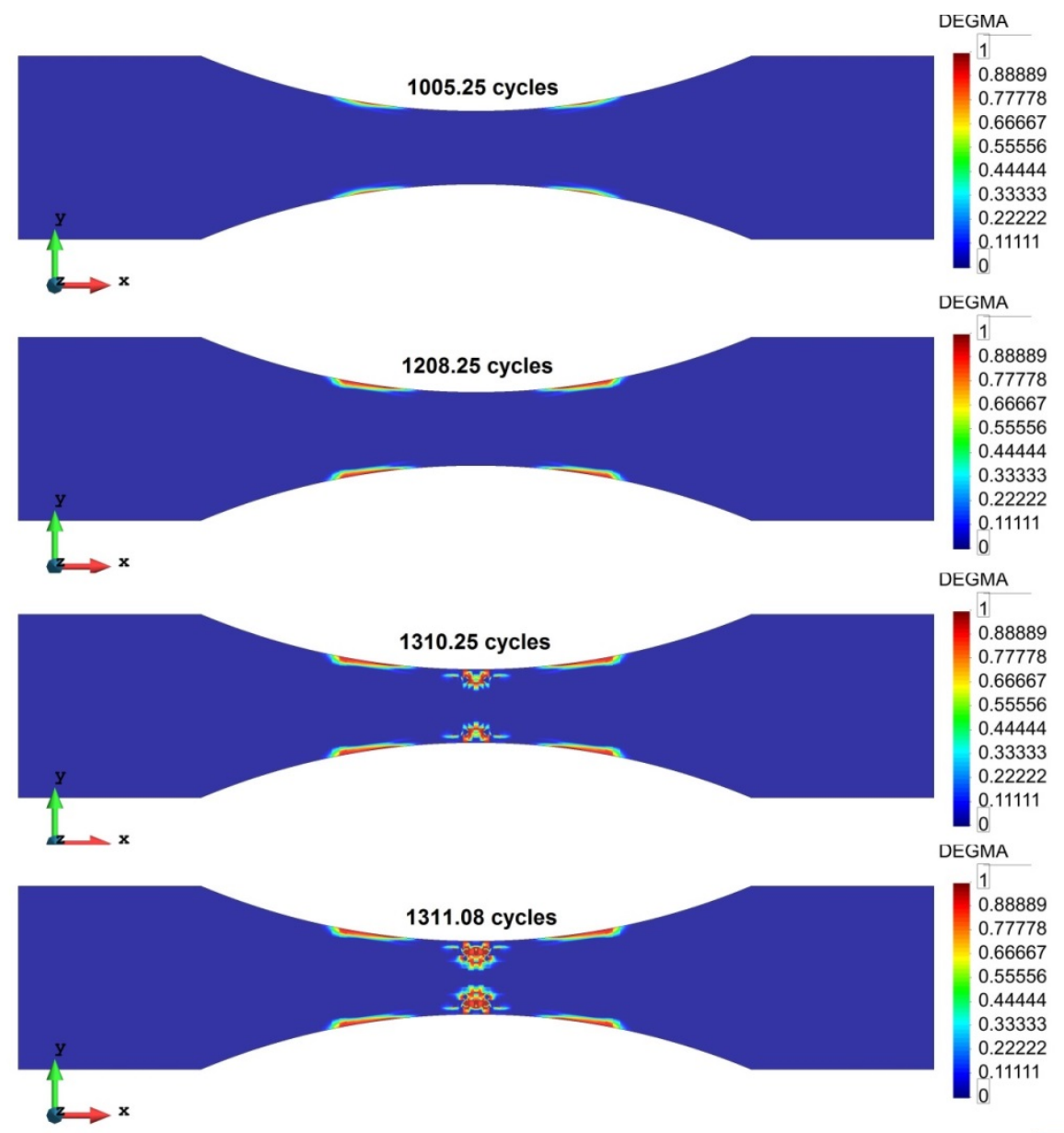

GiD

Figure 14. Distribution of the damage parameter in the isophtalic matrix at different time steps

A zoom on the central damaged area of the specimen is shown in Figure 15.

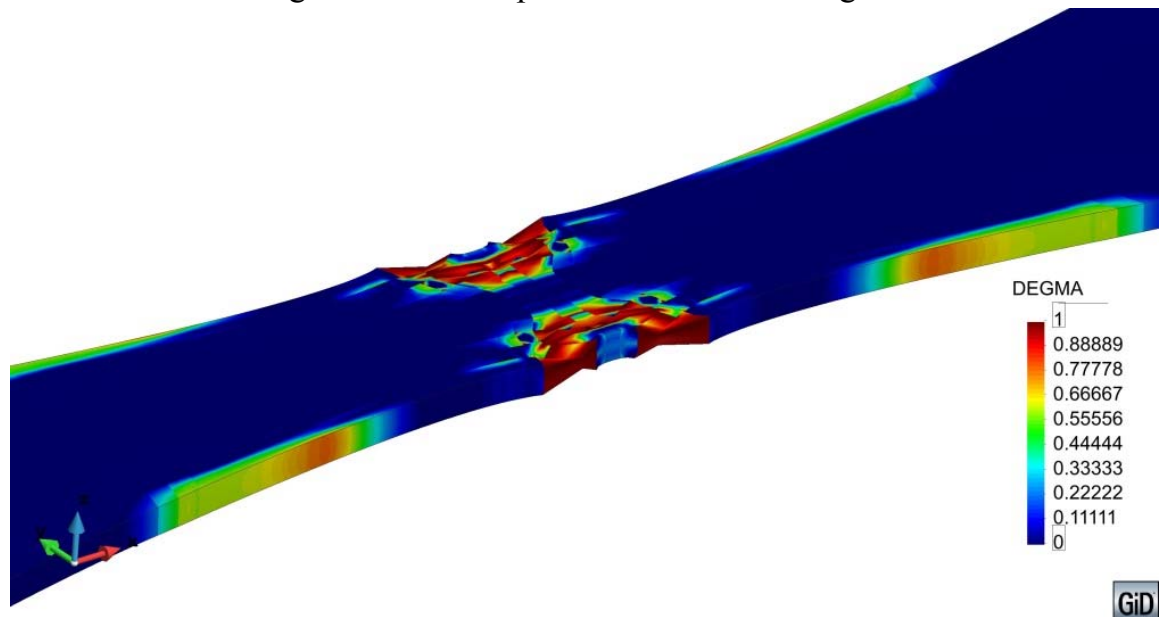

Figure 15. Composite damage distribution in the last step of the analysis on the scaled deformed specimen shape (20x)

The distribution of the damage parameter for the composite material is shown on the scaled deformed shape of the specimen. Again, it can be observed that failure is caused due to damage in the central area, also visible when observing the longitudinal strain distribution in the last step of the analysis (Figure 16). 


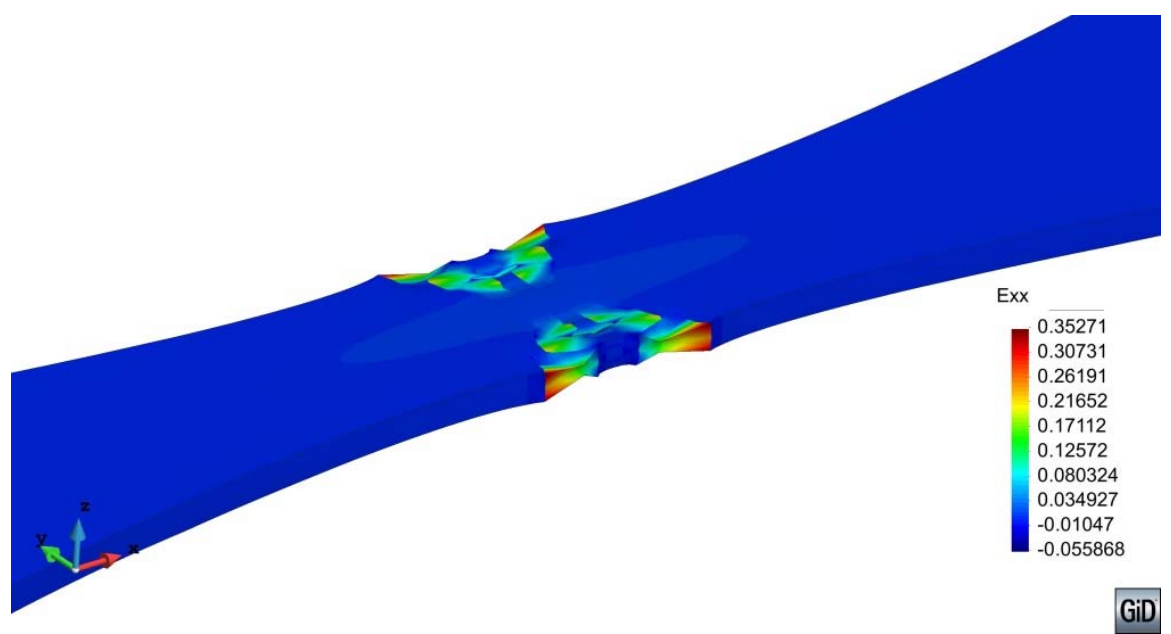

Figure 16. Distribution of the longitudinal strain of the composite in the last step of the analysis on the deformed specimen shape (20x)

Figure 17 shows the evolution of the curves of interest for the fatigue model at the first integration point where damage initiates in the model. The number of cycles is shown in a logarithmic scale on the horizontal axis. Since damage initiates in the isophtalic matrix these curves refer to the matrix material. In Figure 17, the evolution of the equivalent stress in the undamaged space can be seen. This equivalent stress has been calculated with a Von Mises surface and its evolution shows how the load advancing strategy functions at integration point level.

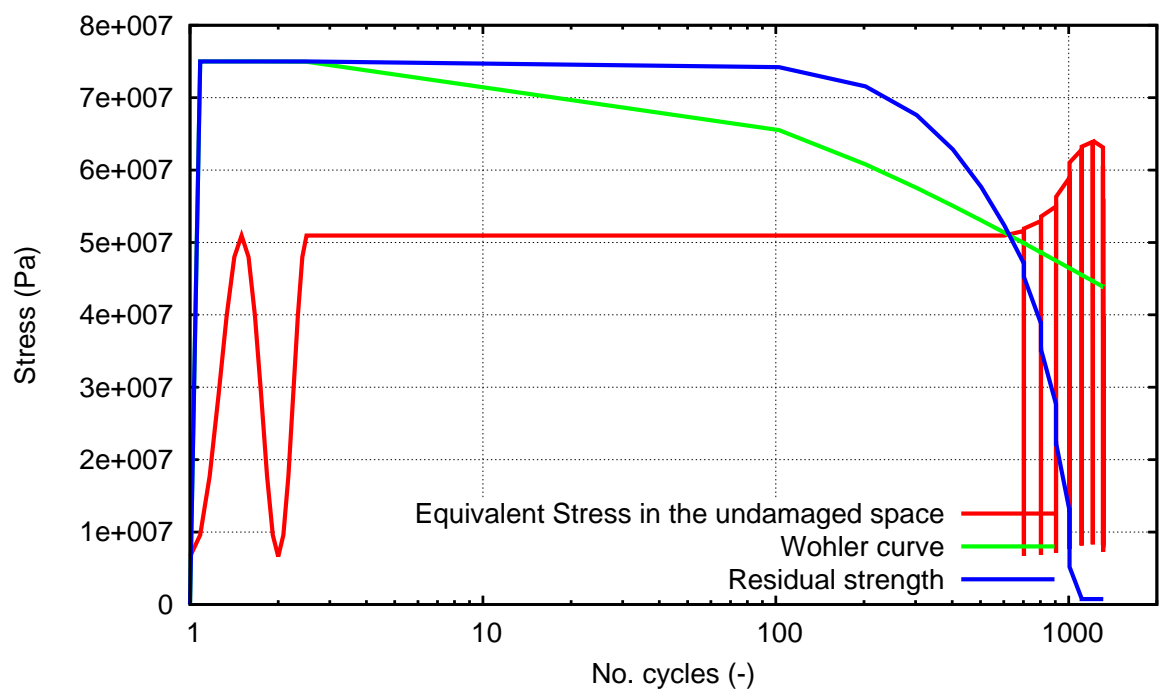

Figure 17. Evolution of the curves of interest for the fatigue model at the first integration point where damage initiates in the model

First, the equivalent stress follows a sinusoidal curve while in the load-tracking stage of the advancing algorithm. When the stress state has stabilized from one cycle to the next in the entire geometry the large increments stage begins, where the applied displacement is maintained constant at its maximum value and the free variable number of cycles increases. In this stage, the stress state does not change from one increment to the next, only the material strength threshold and the Wöhler Stress change as indicated in Figure 17. The strength threshold at that material point is lowered progressively until it reaches the maximum equivalent stress and the damage parameter starts to accumulate. The evolution of the internal damage variable can be seen in Figure 18 for the same material point as above. It can be seen that only damage in the matrix accumulates since only the matrix threshold has been surpassed. 


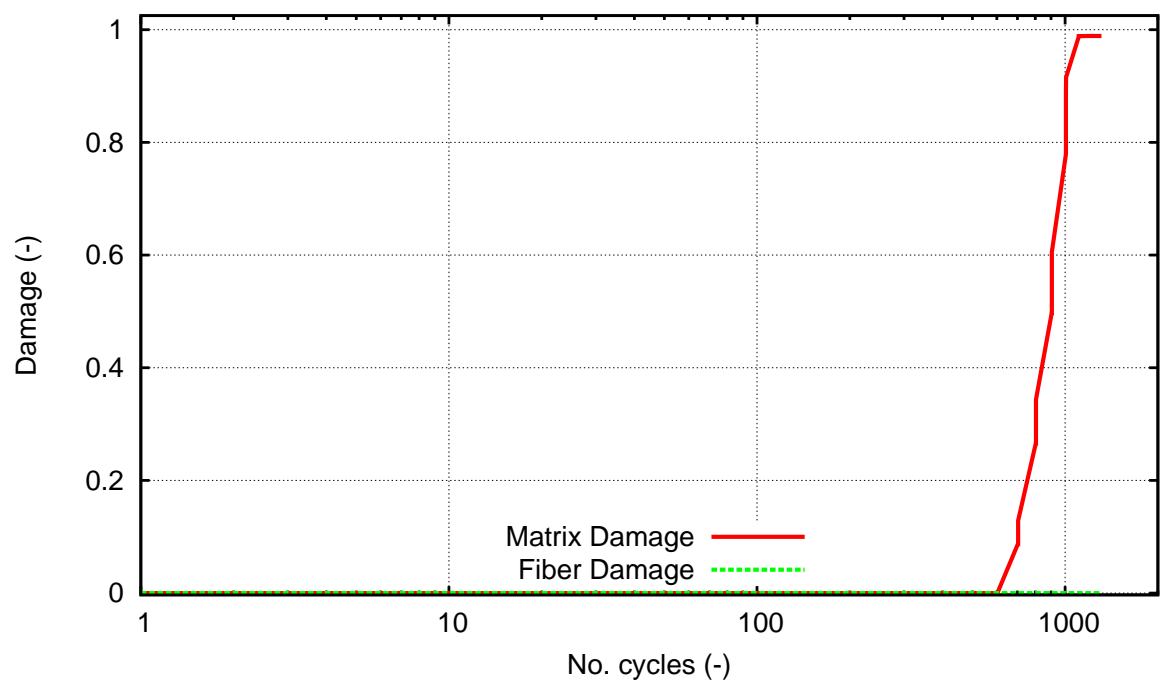

Figure 18. Evolution of the damage internal variables at the first integration point where damage initiates in the model

The nonlinear stress-strain material behaviour in the isophtalic matrix can be seen in Figure 19. When the strength threshold is crossed for the first time a drop in stress is visible. When unloading after this point a corresponding change in stiffness has happened and progressively the matrix load bearing capacity is degraded until failure at that material point. Each jump in stresses is the consequence of another large increment of number of cycles being applied. It can be seen that although the applied maximum displacement of the specimen is constant, a slight reduction of the maximum strain is visible as the stress history of this material point is pushed further in the nonlinear domain. This is a consequence of the structural macro behaviour of the specimen.

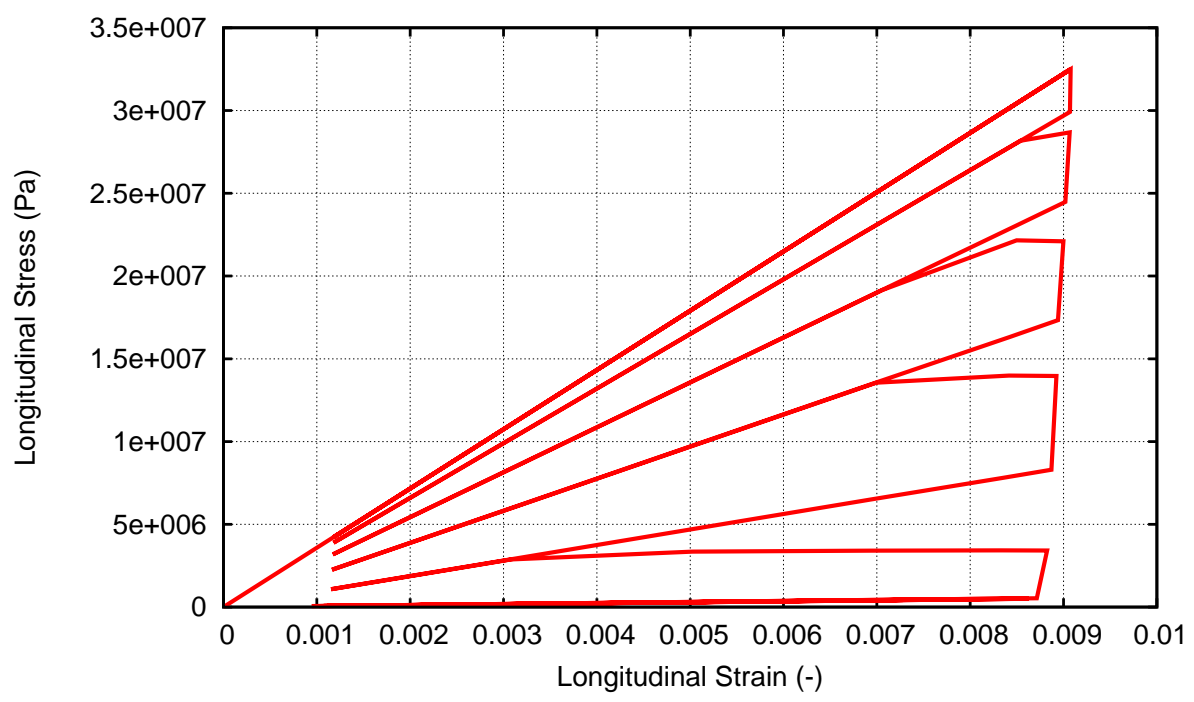

Figure 19. Evolution of the matrix stress-strain at the first integration point where damage initiates in the model

In Figure 20 and Figure 21 the fatigue curves of interest are shown in one of the integration points situated in the center of the sample, at the exact position where the strain gauges are located (see Figure 5). When assessing the evolution of the equivalent stress in the material, it can be seen that it is virtually unchanged, demonstrating an elastic behaviour, up until the very last analysis steps when there is a sudden increase. This corresponds to the moment in load history when damage has propagated enough into the central width that the remaining material area is unable to bear the applied displacement and sudden structural failure occurs. 


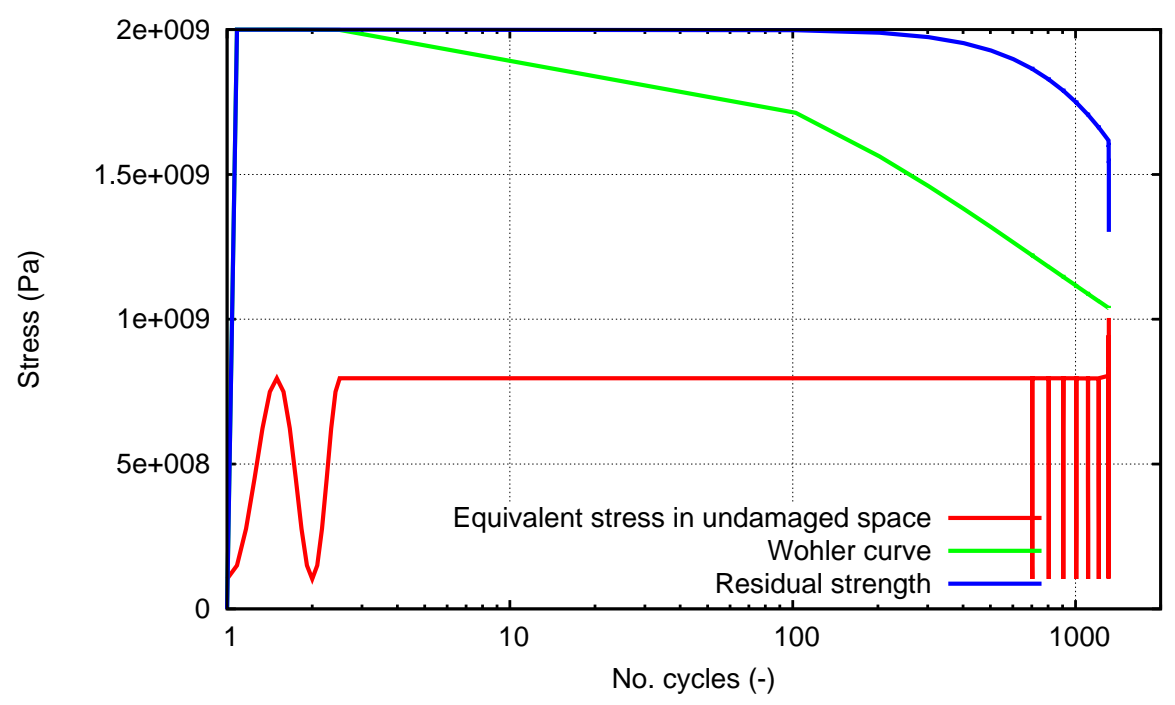

Figure 20. Evolution of the curves of interest for the fatigue model in the fiber of one of the integration points situated at the location of the strain gauge in the experiment

From Figure 20 and Figure 21 it can be seen that the behaviour in this area of the FE model is the same in both matrix and fiber. The equivalent stress evolution present in the two figures is in accordance to the experimental recordings, indicating a brittle failure mode.

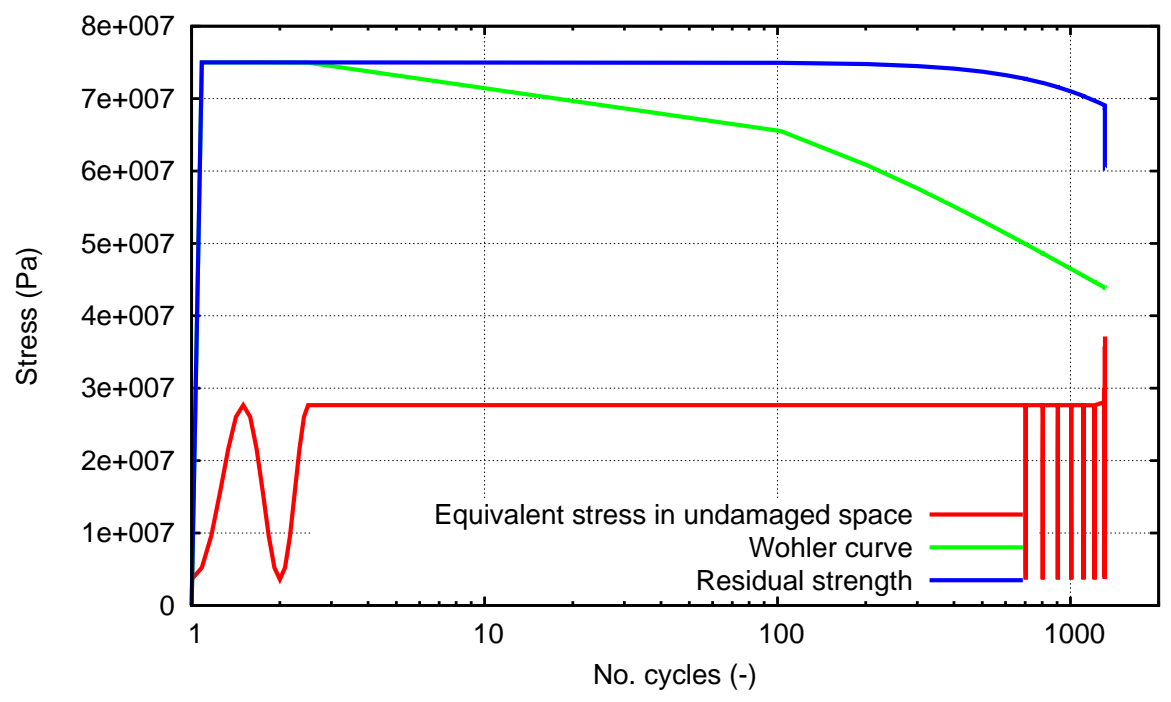

Figure 21. Evolution of the curves of interest for the fatigue model in the matrix of one of the integration points situated at the location of the strain gauge in the experiment

\subsubsection{S-N fatigue life curves}

The comparison between the numerical and experimental S-N curves is shown in Figure 22. These curves are in semi-logarithmic representation. The last point of the chart, corresponding to a ratio of 0.22 between the maximum induced stress at the strain gauge location and the experimentally recorded UTS, represents a cyclic test where the specimen has not failed even after applying $10^{9}$ cycles of loading. 


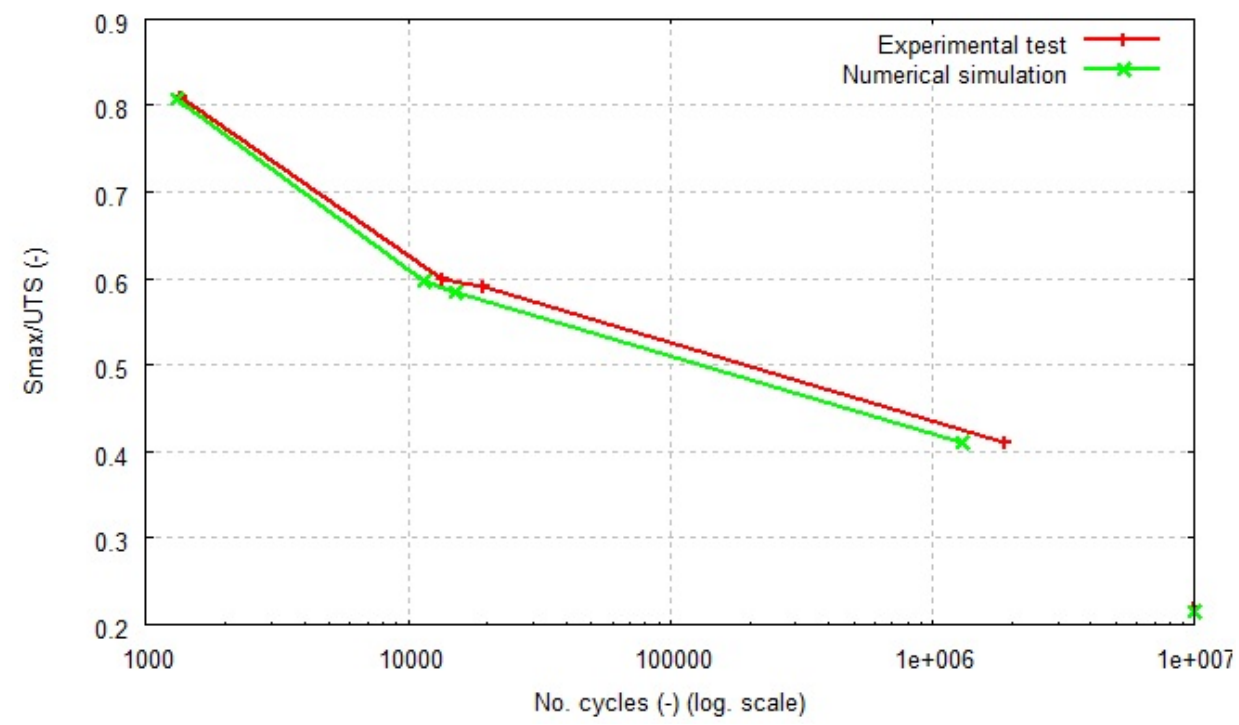

Figure 22. Comparison between the numerical and experimental S-N curves

The test used in the calibration of the fatigue material parameters and the fracture energy was the first one, where the two curves coincide. The corresponding ratio between the maximum induced stress at the strain gauge location and the experimentally recorded UTS was 0.82 . The remaining simulations have been ran with the matrix and fiber material properties obtained from the calibration process. It can be seen that the life prediction capabilities of the model progressively worsen as the stress ratio lowers, which is to be expected since the error tends to be higher the farther away we are from the calibration case.

This tendency can either be a consequence of the test chosen for the calibration; a consequence of the assumptions the model takes into account at splitting the experimental S-N recording into matrix and fiber $\mathrm{S}-\mathrm{N}$ values, or of the assumption that the fiber and matrix both exhibit nonlinear effects due to fatigue.

In Table 5 a summary of all the results, both numerical and experimental, is presented.

\begin{tabular}{|c|c|c|c|c|c|}
\hline Specimen & $\begin{array}{l}\text { Maximum/ } \\
\text { ultimate } \\
\text { load }(\%)\end{array}$ & $\begin{array}{l}\text { Amplitude } \\
\text { ratio } R\end{array}$ & $\begin{array}{l}\text { Cycles to } \\
\text { failure } N_{\mathrm{f}} \\
\text { (experim } \\
\text { ental) }\end{array}$ & $\begin{array}{l}\text { Cycles to } \\
\text { failure } N_{\mathrm{f}} \\
\text { (numerical) }\end{array}$ & Remarks \\
\hline TP5-1 & 82 & 0.13 & 1346 & 1311 & \\
\hline ТP5-2 & 60 & 0.13 & 13407 & 11522 & \\
\hline TP5-3 & 59 & 0.13 & 19159 & 15024 & \\
\hline ТР5-4 & 41 & 0.13 & 1875940 & 1300020 & \\
\hline TP5-5 & 22 & 0.15 & 5000000 & 5000000 & not failed \\
\hline
\end{tabular}

\section{CONCLUSIONS}

This paper presents a fatigue formulation that takes into account the effects caused by the accumulation of number of cycles of loading by an alteration in the strength and in the stiffness of the material. First, material strength is reduced until it reaches the induced maximum stress level. From that point on, energy dissipation is done by means of stiffness reduction.

The cyclical load is taken into consideration by means of two parameters: maximum stress generated by the applied load and stress reversion factor. Both parameters have a direct influence on the onset of damage and on the strength reduction. This allows a quantification of the effects induced by different cyclical loads and discrimination between different load-applying sequences. 
In order to take full advantage of this formulation a stepwise load advancing strategy has been used with the aim of saving computational time. The procedure divides the load in two different loading processes: load tracking and large increments phases. The jump between the two loading schemes is made automatically, depending on the mechanical response of the structure. The algorithm is user controlled by means of the stabilization tolerance and by the number of cycles considered as large step.

The constitutive model has been used for both the fiber and the matrix of a composite material and the composite material behaviour has been formulated by means of the serial/parallel rule of mixtures. The possibilities of this constitutive strategy have been studied for the case of a pultruded glass fiber reinforced polymer. For this case, a calibration of the material parameters has been made with one of the experimental tests and the resulting material has been used for the rest of the simulations.

The results showed a progressively higher discrepancy between the experimental fatigue life and the numerical one, the lower the maximum stress induced in the specimen. This tendency is believed to be a consequence of the assumptions the model takes into account at splitting the experimental S-N recording into matrix and fiber S-N values, or of the assumption that the fiber and matrix both exhibit nonlinear effects due to fatigue.

Regarding the failure mode, the experimental results showed diagonal cracks formed in the outer layers containing the combined mats. However, the failure mode in the numerical simulations did not exhibit diagonal cracks. This discrepancy may be due to the fact that the combined mats were not discretized in the numerical model, their effect being quantified in a homogenized way.

\section{Acknowledgements}

This work has been partially supported by the Spanish "Ministerio de Economía y Competividad" through the project BIA2015-67807-R - RESCICLO.

\section{REFERENCES}

[1] Commission on Engineering and Technical Systems, 1991, Assessment of Research Needs for Wind Turbine Rotor Materials Technology, Washington, D.C.: National Academy Press.

[2] Huston, R.J., 1994, Fatigue life prediction in composites, Journal of Pressure Vessel Technology, 59:131-140.

[3] Kachanov, L. M. Introduction to Continuum Damage Mechanics, Martinus Nijhoff, The Netherlands; 1986.

[4] Chen, A.S., Almond, D.P., Harris, B., 2001, "Real time monitoring of fatigue-induced damage growth in composite materials by Acoustography", Composite Sci. \& Tech.,61: 2437-2444.

[5] Schulz, A.,Sayer,F.,van Wingerde, A., 2011, "Experimental investigation of the influence of plydrop geometry on the fatigue behavior of tapered composites", Proceedings of the 3rd Thematic Conference on the Mechanical Response of Composites, Hannover, Germany, September 21-23

[6] Firehole Composites, 2010, "Fatigue life prediction in composite materials", White Paper Series, "http://www.firehole.com/documents/ WP_Fatigue-Life-Prediction-in-Composite-Materials.pdf"

[7] Hashin, Z., Rotem, A., 1973, "A fatigue failure criterion for fiber reinforced materials", Journal of Composite Materials, vol. 7:448-464, 1973.

[8] J. Halpin, T. Johnson, and M. Waddups. Kinetic fracture models and structural reliability. Int J Fract Mech, 8:465 - 468, 1972.

[9] H. Halvarson, W. Curtin, and K. Reifsnider. Fatigue life of individual composite specimens based on intrinsic fatigue behavior. Int J Fatigue, 19(5):369 - 377, 1996.

[10] T. OBrien and K. Reifsnider. Fatigue damage evaluation through stiffness measurements in boron epoxy laminates. J Compos Mat, 15:55 - 70, 1981.

[11] K. Reifsnider. The critical element model: A modeling philosophy. Eng Fract Mech, 25:739 - 749, 1986.

[12] K. Reifsnider, S. Case, and J. Duthoit. The mechanics of composite strength evolution. Compos Sci 
Tech, 60:2539 - 2546, 2000.

[13] K. Reifsnider and W. Stinchcomb. A critical element model of the residual strength and life of fatigueloaded composite coupons. Composite Materials: Fatigue and Fracture, ASTM STP, 907:298 - 313, 1986.

[14] D. Song and N. Otani. Fatigue life prediction of cross-ply composite laminates. Mat Sci Eng, A238:329 - 335, 1977.

[15] A. Charewicz and I. Daniel. Damage mechanisms and accumulation in graphiteepoxy laminates. Composite Materials: Fatigue and Fracture, ASTM STP, 907:274 - 297, 1986.

[16] E. Gamstedt and B. Sjgren. An experimental investigation of the sequence effect in block amplitude loading of crossply composite laminates. Int J Fatigue, 24:437 - 446, 2002.

[17] T. Philippidis and V. Passipoularidis. Residual strength after fatigue in composites: Theory vs. experiment. Int J Fatigue, 29(12):2104 - 2116, 2007.

[18] L. Broutman and S. Sahu. A new theory to predict cumulative fatigue damage in fiber glass reinforced plastics. Composite materials: testing and design (2nd Conference), ASTM STP, 497:170 - 188, 1972.

[19] T. Adam, R. Dickson, C. Jones, H. Reiter, and B. Harris. A power law fatigue damage model for fiber reinforced plastic laminates. Proc Instn Mech Engrs, 200(C3):155-166, 1986.

[20] Barbu, L.G., Oller, S., Martínez, X. and Barbat, A.H. Stepwise advancing strategy for the simulation of fatigue problems. Proceedings of the 12th International Conference on Computational Plasticity Fundamentals and Applications, COMPLAS 2013: 1153-64.

[21] Barbu, L.G., Oller, S., Martinez, X. and Barbat, A. High cycle fatigue simulation: A new stepwise load-advancing strategy, Engineering Structures (2015) 97: 118-129, http://dx.doi.org/10.1016/j.engstruct.2015.04.012.

[22] Martinez, X.; Oller, S.; Barbero, E.J. Study of delamination in composites by using the serial/parallel mixing theory and a damage formulation. 1st ECCOMAS Thematic Conference on Mechanical Response of Composites. Porto, Portugal, 12-14 September 2007.

[23] Martinez, X.; Oller, S.; Barbero, E. Study of delamination in composites by using the serial/parallel mixing theroy and a damage formulation. Chapter in Mechanical response of composites. Ed. Pedro Camanho et al. pp. 119 - 140. Springer, 2008. ISBN 978-1-4020-8583-3

[24] Oller, S., Salomón, O. and Oñate, E. A continuum mechanics model for mechanical fatigue analysis, Comput Mat Sci 2005; 32:175-95.

[25] Schijve, J. Fatigue of Structures and Materials, 2nd ed. Berlin: Springer-Verlag; 2009.

[26] Fatemi, A. and Yang, L. Cumulative fatigue damage and life prediction theories: a survey of the state of the art for homogeneous materials, Int J Fat 1998; 20:9-34.

[27] Kachanov, L. M. Time to the rupture process under creep conditions, Izv. Akad. Nauk. SSR Otd. Tech. Nauk. 1958; 8:26-31.

[28] Chaboche, J.L. Fracture mechanics and damage mechanics: complementarity of approaches, In Numerical Methods in Fracture Mechanics, Proceedings of the Fourth International Conference 1987: 309-24.

[29] Chaboche, J.L. A differential law for nonlinear cumulative fatigue damage, In Materials and Building Research, Annales de l'ITBTP 1974; 39:117-24.

[30] Lemaitre, J. and Chaboche J. L. Mechanics of Solid Materials , Cambridge University Press, U.K.; 1990.

[31] Lemaitre, J. and Chaboche J. L. Aspect phenomenologique de la rupture par endommagement, J Mech App 1978; 2(3):317-65.

[32] Wang, J. A continuum damage mechanics model for low-cycle fatigue failure of metals, Engng Fract Mech 1992; 41(3):437-41.

[33] Wang, T. and Lou, Z. A continuum damage model for weld heat affected zone under low-cycle fatigue loading, Engng Fract Mech 1990; 37(4): 825-9.

[34] Li, C., Qian, Z. and Li, G. The fatigue damage criterion and evolution equation containing material microparameters, Engng Fract Mech 1989; 34(2):435-43. 
[35] Li, S., Wang, M., Jeanmeure, L., Sitnikova, E., Yu, F., Pan, Q., Zhou, C. andTalreja, R. Damage Related Material Constants in Continuum Damage Mechanics for Unidirectional Composites with Matrix Cracks. International Journal of Damage Mechanics, 2018. doi:10.1177/1056789518783239.

[36] Talreja R., A continuum mechanics characterization of damage in composite materials. Proc R Soc Lond A Math Phys Eng Sci (1985), 399(1817): 195-216.

[37] Voyiadjis GZ and Kattan PI A comparative study of damage variables in continuum damage mechanics. International Journal of Damage Mechanics (2009) 18(4): 315-340.

[38] Maimí P, Camanho PP, Mayugo JA, et al. A continuum damage model for composite laminates: Part I - Constitutive model. Mechanics of Materials (2007), 39(10): 897-908.

[39] Hajikazemi M, Sadr MH and Talreja R Variational analysis of cracked general cross-ply laminates under bending and biaxial extension. International Journal of Damage Mechanics (2015), 24(4): 582624.

[40] Goidescu C, Welemane H, Pantalé O, et al. Anisotropic unilateral damage with initial orthotropy: A micromechanics-based approach. International Journal of Damage Mechanics (2015), 24(3): 313337.

[41] Brünig M A thermodynamically consistent continuum damage model taking into account the ideas of CL Chow. International Journal of Damage Mechanics (2016), 25(8): 1130-1141.

[42] Ayadi W, Laiarinandrasana L and Sai K Anisotropic (continuum damage mechanics)-based multimechanism model for semi-crystalline polymer. International Journal of Damage Mechanics (2018), 27(3): 357-386.

[43] Turon, A., Costa, J., Camanho, P. P., Dávila, C. G., 2007. Simulation of delamination in composites under high-cycle fatigue. Composites: Part A 38, 2270-2282.

[44] Khoramishad, H., Crocombe, A. D., Katnam, K. B., Ashcroft, I. A., 2010. Predicting fatigue damage in adhesively bonded joints using a cohesive zone model. International Journal of Fatigue 32, 11461158.

[45] Harper, P. W., Hallett, S. R., 2010. A fatigue degradation law for cohesive interface elements Development and application to composite materials. International Journal of Fatigue 32, 17741787.

[46] Giuliese, G., Pirondi, A., Moroni, F. 2014, A cohesive zone model for three-dimensional fatigue debonding/delamination, Procedia Materials Science, 3, 1473 - 1478.

[47] Rubiella, C., Hessabi, C.A. \& Fallah, A.S. 2018, "State of the art in fatigue modelling of composite wind turbine blades", International Journal of Fatigue, vol. 117, pp. 230-245.

[48] Holman, R. K. , Liaw, P. K., Methodologies for predicting fatigue life, JOM: the journal of the Minerals, Metals \& Materials Society 1997; 49(7):46-52.

[49] Palmgren, A.,Die Lebensdauer von Kugellagern (The service life of ball bearings), Zeitschrift des Vereines Deutscher lngenieure 1924; 68(14):339-41.

[50] Miner, M. Cumulative fatigue damage, J Appl Mech 1945; 12:159-64

[51] Vasudevan,A.K, Sadananda, K, Glinka, G. Critical parameters for fatigue damage Int J Fat 2001; 23(1): 39-53

[52] Halford, G.R. Cumulative fatigue damage modeling — crack nucleation and early growth, Int J Fat 1997; 19(1):S253-60

[53] Hoeppner, D. W., Krupp, W. Prediction of component life by application of fatigue crack growth knowledge, Engng Fract Mech 1974; 6:47-70.

[54] Llobet, J., Maimí, P., Essa, Y., Martin de la Escalera, F. 2019, Progressive matrix cracking in carbon/epoxy cross-ply laminates under static and fatigue loading, International Journal of Fatigue, 119, pp. 330-337.

[55] Lubliner, J. Plasticity Theory, Macmillan Publishing, U.S.A.; 1990.

[56] Luccioni, B., Oller, S. and Danesi, R. Coupled plastic-damage model, Comp Meth App Mech Eng 1996; 129:81-90.

[57] Malvern, L. Introduction to the Mechanics of Continuous Medium, Prentice Hall, U.S.A.; 1969. 
[58] Lubliner, J. On thermodyamics foundations of non-linear solid mechanics, Int J Non-Lin Mech 1972; 7: 237-54.

[59] Maugin, G. The Thermomechanics of Plasticity and Fracture, Cambridge University Press, U.K.; 1992.

[60] Simo, J. and Ju, J. Strain and stress based continuum damage models - I Formulation, Int J Solids Struct 1987; 23: 821-40.

[61] Oliver, J., Cervera, M., Oller, S., and Lubliner, J. Isotropic damage models and smeared crack analysis of concrete, In Second international conference on computer aided analysis and design of concrete structures $1990 ; 2: 945-58$.

[62] Oller, S. Dinamica no-lineal, CIMNE, Nro. 63, Barcelona, Spain, 2003. ISBN 84-89925-95-X

[63] Salomón, O., Oller, S. and Oñate, E. Fatigue Analysis of Materials and Structures Using a Continuum Damage Model, Int J Forming Processes 2002; 5: 493-503.

[64] Suero, A. and Oller, S. Tratamiento del Fenómeno de Fatiga Mediante la Mecánica de Medios Continuos, Monografía CIMNE No 45, Barcelona, Spain ;1998.

[65] Oller, S., Oñate, E., Canet, J. Miquel and Botello, S. A plastic damage constitutive model for composite materials, Int J Solids Struct 1996; 33:2501-18.

[66] Barbu, L. G., Numerical simulation of fatigue processes: application to steel and composite structures. $\mathrm{PhD}$ Thesis, UPC, 2016.

[67] F. Rastellni, S. Oller, O. Salomon, E. Oñate Composite materials non-linear modeling for long fiber reinforced laminates: continuum basis, computational aspects and validations, Comput Struct, 86 (9) (2008), pp. 879-896

[68] O. Salomon, F. Rastellini, S. Oller, E. Onate, Fatigue prediction for composite materials and structures. NATO Research and technology Organisation (RTO) Eds. Air Vehicle Technology: AVT121. Symposium on the evaluation, control and prevention of high cycle fatigue, Granada, Spain, 2005.

[69] T. Keller, T. Tirelli, A. Zhou Tensile fatigue performance of pultruded glass fiber reinforced polymer profiles, Compos Struct, 68 (2) (2005), pp. 235-245

[70] Martinez, X., Oller, S., Rastellini, F. and Barbat, A. A numerical procedure simulating RC structures reinforced with FRP using the serial/parallel mixing theory, Comp \& Struct 2008; 86(15-16):160418.

[71] Martinez, X., Oller, S., Barbu, L.G. and Barbat, A.H. Analysis of ultra low cycle fatigue problems with the Barcelona plastic damage model, Proceedings of the 12th International Conference on Computational Plasticity - Fundamentals and Applications, COMPLAS 2013; 352-63.

[72] Martinez, X., Oller, S., Barbu, L., Barbat, A. and De Jesus, A.M.P. Analysis of ultra-low cycle fatigue problems with the Barcelona plastic damage model and a new isotropic hardening law, Int. J. Fat. 2015; 73:132-42.

[73] Barbu, L.G., Oller, S., Martínez, X. and Barbat, A.H Coupled plastic damage model for low and ultralow cycle seismic fatigue. 11th. World Congress on Computational Mechanics 2014; 2955-66, ISBN 978-84-942844-7-2.

[74] Barbu, L.G., Martinez, X., Oller, S. and Barbat, A.H. Validation on large scale tests of a new hardening-softening law for the Barcelona plastic damage model, Int. J. Fat. 2015; 81:213-226.

[75] Barbu, L.G., Oller, S., Martínez, X. and Barbat, A.H. Model-wise algorithm for the resolution of fatigue problems, Proceedings of the 13th International Conference on Computational Plasticity Fundamentals and Applications, COMPLAS 2015; 260-271.

[76] Barbu, L.G., Martinez, X., Oller, S. and Barbat, A.H. Large scale validation of a new isotropic hardening law for the Barcelona plastic damage model under Ultra Low Cycle Fatigue conditions, Proceedings of the 13th International Conference on Computational Plasticity - Fundamentals and Applications, COMPLAS 2015; 248-259.

[77] T. Keller, T. Tirelli Fatigue behavior of adhesively connected pultruded GFRP laminates, Compos Struct, 65 (1) (2004), pp. 55-64 
[78] AzoM.com, E-Glass Fibre <https://www.azom.com/properties.aspx?ArticleID=764> 